Discussion Paper No. 877

WAITING FOR SIGNALLING QUALITY

Hikmet Gunay

July 2013

The Institute of Social and Economic Research

Osaka University

6-1 Mihogaoka, Ibaraki, Osaka 567-0047, Japan 


\title{
Waiting For Signalling Quality
}

\author{
Hikmet Gunay* \\ University of Manitoba
}

July 26, 2013

\begin{abstract}
When a durable good of uncertain quality is introduced to the market, some consumers strategically delay their buying to the next period with the hope of learning the unknown quality. We analyze the monopolist's pricing and "waiting" strategies when consumers have strategic delay incentives. We show when the monopolist offers introductory low prices in pooling equilibria. We also find two types of separating equilibria: one where high type signals its quality by choosing a different price than the low type in the first period, and another where the high-type monopolist announces the product in the first period and waits to sell only in the second period. Waiting creates a credible cost for signalling; hence, the monopolist uses it as a signalling device.
\end{abstract}

JEL Codes: C73, D42, D83, L12

Keywords: Strategic delay, Introductory prices, Penetration pricing, Cream-skimming, Monopoly pricing, Coasian dynamics.

*I am greatful to M. Aoyagi and anonymous referees for their suggestions. I also thank I. Ishibashi, S.Loertscher, M. Mitchell, R. Wang, S. M. Gorricho for their suggestions on an earlier version, and Osaka ISER for hosting me during doing this research, and U of Manitoba for providing financial assistance. I thank Xin Meng for her superb research assistance. An earlier version of this paper is presented at Bilkent, Ryerson, Osaka (ISER), York, Melbourne, Saskatchewan, Windsor, Ritsumeikan, Hiroshima, Kobe, and the IIOC Conference held in Savannah, Midwest Economic Theory Conference held at the U. of Minnesota and Delta Marsh Conference held at the U. of Manitoba; I thank the participants for their suggestions. The usual disclaimer applies. 


\section{Introduction}

Microsoft finished Windows 7 before July, 2009; however, the launch date was set as October 22, 2009. ${ }^{1}$ In the meantime, consumers heard about the quality of Windows 7 -e.g., comparison with Vista- through magazines such as Business Week. In this paper, we give one possible explanation of why a monopolist announces a later launch date rather than selling its product right away. We show that such a waiting strategy signals high quality.

In this paper, we not only analyze seller's waiting incentives but also consumers' waiting incentives. Specifically, when a new product is introduced to the market, only a few consumers buy it right away. The others wait and then decide whether or not to buy. We show that there are two reasons for this waiting. First, consumers wait to learn more about the unknown quality of the good (strategic delay effect, an effect neglected in the literature). Second, they wait to take advantage of the lower price, if the price will decrease (price effect, a well-known reason in the literature). We analyze firms' pricing strategies with these two effects and relate it to the practice of low introductory prices, and the strategy of waiting before selling.

In our model, a continuum of consumers decide whether to buy one unit of a durable good in one of the two periods. A consumer's total willingness to pay for the good depends on the consumer's taste for quality (private value) and the good's unknown intrinsic quality (common value). Consumers' taste for quality is uniformly distributed. The quality of the product is revealed in the second period. This uncertainty resolution makes the consumers with moderate preferences delay their buying strategically. By delaying her purchase, the consumer avoids buying a low quality good. However, she gives up the utility she could have derived from a high quality good in the first period. The monopolist who knows its product's quality and decides how to price it and when to start selling it when there are both strategic delay and price effects.

We use Perfect Bayesian Equilibrium to solve our two period signalling model. We find two types of separating and one type of pooling equilibria depending on the parameters. In all pooling equilibria, we find the same sufficient condition for the monopolist to offer

\footnotetext{
${ }^{1}$ Business Week, October 26, 2009, page 71.
} 
introductory low prices or to use a cream-skimming strategy.

The monopoly pricing literature is a huge one, and can be divided into durable goods (e.g. Coase (1972), Gul et. al. (1986), Stokey (1979)) and experience goods literature. The experience goods literature focuses on introductory pricing (e.g., Shapiro (1983), Cremer (1984), Bagwell (1987), Schlee (2001), Bergemann and Valimaki (2006)) or price discrimination to new and repeat customers (Jing (2011)). ${ }^{2}$ In the aforementioned "experience goods" papers, consumers learn their private valuation by "experiencing" the good; hence, they neither discuss signalling quality nor consumers' strategic delay. (unlike this "durable goods" paper). ${ }^{3}$ In other experience goods papers (e.g. Milgrom and Roberts (1986)), signalling via pricing is discussed but consumers' strategic delay incentive does not exist.

We have two kinds of separating equilibria. In the first one, the high type monopolist announces the product launch date in the first period and sells its product only in the second period although the product is ready from the start. Our paper's innovation is to show that waiting before selling serves as a signalling strategy, and that consumers have the option of delaying their buying. There are "vaporware" papers that show why some firms announce launch dates before the product is ready (e.g., Bayus et al. (2001), Dranove and Gandal (2003), Kristiansen (2006), Choi et al. (2010)). ${ }^{4}$ Unlike these papers, our firm's product is ready in the first period but the firm chooses not to sell at that time in order to signal its quality. ${ }^{5}$ Waiting creates a credible cost for signalling; hence, the high-type monopolist uses this as a signalling device.

In the other type of separating equilibrium, low and high types each chooses different prices in the first period. Both low and high type use high and declining prices in such an equilibrium; in order to sell to the residual "low willingness to pay consumers" in the second period, they have no choice but to lower the price. Our model is different than Bagwell and

\footnotetext{
${ }^{2}$ These papers generally discuss cream-skimming like our paper.

${ }^{3}$ Van Ackere and Reyniers (1995) is a quasi-durable good paper that explains introductory offers (and trade-ins). Their model also does not have strategic delay.

${ }^{4}$ Vaporware means falsely announcing product launch dates.

${ }^{5}$ Some firms present their products in expos for the public; hence, experts and consumers can verify that the product is ready. For example, Sony showed its PlayStation 4 console (PS4) in E3-2013 Expo but Sony made the announcement that it will release PS4 in Holiday 2013 season (which is November) according to various websites including www.pcadvisor.co.uk
} 
Riordan (1991) (quality is learned in the second period, there are no expert consumers etc.) so the different result, in the sense that low type also uses high and declining price, is not surprising.

The theme of this paper is also related to the literature on the durable good monopolist in which buyers' incentive to delay purchases causes the monopolist to reduce prices immediately (Coase (1972), Gul et. al. (1986)) and the intertemporal price discrimination literature in which prices fall as time passes (Stokey (1979), Landsberger and Meilijson (1985), Tirole (1989)). Our paper extends these papers to allow for uncertainty on the common value component (quality) of consumers' total willingness to pay. We show that price increase is possible in the short term, although "the higher willingness to pay" consumers, in terms of pure private value, bought their unit demand in the first period and exited the market. In the second period, the residual "lower willingness to pay" consumers learn that the good's quality is much higher than their expectation. Then, the high-type monopolist can charge a higher second period price in a pooling equilibrium.

Our paper also falls into the strategic delay literature (e.g., Aoyagi (1998), Heidhues and Melissas (2006), Gunay (2008a), Gunay (2008b)). To our best knowledge, there is no paper in this literature that shows how a monopolist will price its good when facing consumers who delay their buying strategically. Bose et. al. (2008) discuss how a monopolist price its goods when faced by one consumer at each period or Bhalla (2011) discusses how a monopolist will price its good when faced with non-strategic consumers; however, their consumers do not have strategic delay incentives. ${ }^{6}$

In what follows, we set up our model. We define our Perfect Bayesian Equilibrium in the Appendix. We use this equilibrium concept to show what type of equilibria exist. We discuss various assumptions and generalizations at the end. All proofs can be found in the Appendix.

\footnotetext{
${ }^{6}$ Lopomo and Squintani (2007) also discuss whether the seller will choose to sell in the spot market or forward market. They assume all consumers have the same type, and the seller has a different discount factor unlike us. As a result, we find different separating equilibria.
} 


\section{The Model}

A monopolist's product is exogenously set to be either high quality $\gamma_{h}=1$ or low quality $\gamma_{l} \in[0,1)$. The monopolist has private information about his type, $\gamma_{i} \in \Psi=\left\{1, \gamma_{l}\right\}$. In the first period, he determines the price, $p_{1}^{i} \in[0, \infty)$ (where $i=H, L$ depending on quality) or announces the launch date as the second period. That is, his action set in the first period is $A_{1 M}=[0, \infty) \bigcup\{$ announce $\}$. A continuum of consumers are indexed by their taste parameters $\theta$ which is uniformly distributed on $\Theta=[0,1]$. Each consumer has a unit demand and believes that $\gamma_{i}=1$ with probability $\alpha>0$ and $\gamma_{i}=\gamma_{l}$, with probability 1- $\alpha{ }^{7}$ After observing the monopolist's action $a_{1 M}$, each consumer updates her belief. We denote this first period posterior by $\mu_{1 B}\left(\gamma_{i}=1 \mid a_{1 M}\right)$. Given their beliefs, each consumer chooses an action $a_{1 B} \in A_{1 B}=\{$ Buy, Delay $\} .{ }^{8}$ The monopolist does not know the type of consumers but knows their taste distribution; therefore, the monopolist cannot price discriminate in any given period.

\begin{tabular}{|c|c|c|}
\hline \multicolumn{2}{|c|}{ FIRST PERIOD } & SECOND PERIOD \\
\hline $\begin{array}{l}\text { Monopolist observes } \\
\text { quality and } \\
\text { sets the price } p_{1}^{i}\end{array}$ & $\begin{array}{l}\text { Consumers } \\
\text { update priors. } \\
\text { Decide whether }\end{array}$ & $\begin{array}{l}\text { Monopolist sets the price } p_{2}^{i} \\
\text { Consumers observe quality and } p_{2}^{i} \text {. } \\
\text { Then decide whether to buy. }\end{array}$ \\
\hline
\end{tabular}

Figure 1: TIMING OF THE GAME

At the beginning of the second period, the true quality of the product is revealed to the "informed" consumers, and in this section we assume all consumers are informed. ${ }^{9}$ Let $h=\left[a_{1 B}\left(\theta, a_{1 M}\right), a_{1 M} \in A_{1 M}, \gamma_{i}\right] \in H$ denote the history that summarizes the actions taken by each player in the first period, the quality revealed in the second period and $H$ denote the history space. In period 2 , the monopolist chooses its second period price $p_{2} \in A_{2 M}=[0, \infty)$

\footnotetext{
${ }^{7}$ This is a durable good since consumers have a unit demand.

${ }^{8}$ If "announce" is chosen by the monopolist, then all consumers delay in the first period.

${ }^{9}$ The justification of this assumption is as follows. Consumer Report style magazines may reveal the product once it is on the market or if some consumers bought the product, they may reveal the true quality to the other consumers by using internet or other forms of media; they have no incentive to misrepresent the true quality since re-selling is not modelled in this paper. We also relax this assumption later by assuming only a fraction $\beta$ of consumers learn the true quality in the second period. Informed consumers, their type denoted by $\tau=I$, learn the quality, and uninformed consumers $\tau=U$ do not learn the quality (unless it is a separating equilibrium).
} 
and then each consumer chooses an action $a_{2 B} \in A_{2 B}=\{$ Buy, Do not Buy $\}$. Consumers beliefs in this period are $\mu_{2 B}: H \times A_{2 M} \times\{I, U\} \mapsto[0,1]$. Since we assume that all consumers are informed $(\tau=I)$ in this section, we have $\mu_{2 B}=1$ if $\gamma_{i}=1$; otherwise $\mu_{2 B}=0$.

A (pure) behavioral strategy $\sigma_{M}$ of the monopolist consists of two mappings: First, $\sigma_{1 M}: \Psi=\left\{\gamma_{l}, 1\right\} \mapsto A_{1 M}$. Second, $\sigma_{2 M}: H \times \Psi \mapsto A_{2 M}$.

A (pure) behavioral strategy $\sigma_{B}$ of the buyers/consumers consists of two mappings: First, $\sigma_{1 B}: \Theta=[0,1] \times A_{1 M} \mapsto A_{1 B} \cdot{ }^{10}$ Second, $\sigma_{2 B}: H \times A_{2 M} \times \Theta \mapsto A_{2 B}$.

Both the consumers and the monopolist have the same discount factor $\delta \in(0,1]$. A type $\theta$ who buys the good in the first period derives an expected utility of $(1+\delta)\left[\left(\mu_{1 B}+(1-\right.\right.$ $\left.\left.\left.\mu_{1 B}\right) \gamma_{l}\right) \theta-p_{1}^{i}\right]$ after observing the price $p_{1}^{i}$. Instead, if she delays buying to the second period, then, looking from the first period, she derives an expected utility of $\delta\left[\mu_{1 B}\left(\theta_{1}-p_{2}^{H}\right)+(1-\right.$ $\left.\left.\mu_{1 B}\right)\left(\theta_{1} \gamma_{l}-p_{2}^{L}\right)\right]$. If she does not buy it at all, she derives a zero utility.

Both type of monopolist's marginal and fixed cost of production are equal to zero. The monopolist maximizes its payoff $u_{M}\left(\sigma_{B}, \sigma_{M}\right)=p_{1} \int_{V} d k+\delta p_{2} \int_{Y} d k$. The sets $V=$ $\left[\theta \mid \sigma_{1 B}\left(\theta, p_{1}\right)=B u y\right]$ and $Y=\left[\theta \mid \sigma_{2 B}\left(\theta, h, p_{2}\right)=B u y\right]$ are the sets of first and second period buyers, respectively. The corresponding integrals give the mass of each set. Since consumers have unit demand, we have $V \cap Y=\emptyset$.

\subsection{Perfect Bayesian Equilibrium}

Our model is a two-period signalling game in which the uncertainty about the monopolist's type will be revealed in the second period. We define our Perfect Bayesian Equilibrium in the Appendix (Definition 1). We first define the sequential rationality conditions for the monopolist and the consumers (Condition 1 and 2). That is, when they reach the second period (given the relevant history), they should act rationally. Condition 3 and 4 show how the monopolist and each consumer choose their strategies in the first period. Condition 5 is the usual Bayesian updating condition for the consumers. We only look for pure strategy equilibria in which consumers use threshold strategies. Specifically, for any $a_{1 M}, p_{2}, h$, there exists $\theta_{1}\left(p_{1}\right)$ and $\theta_{2}\left(h, p_{2}\right)$ such that:

\footnotetext{
${ }^{10}$ Note that buyers observe prices before making a decision. Their history is essentially $\left(h^{t}, p_{t+1}\right), t=0,1$, where $h^{0}$ denotes the null history.
} 


$$
\begin{aligned}
\sigma_{1 B}\left(\theta, a_{1 M}\right) & =\left\{\begin{array}{l}
\text { Buy if } \theta \in\left(\theta_{1}, 1\right] \\
\text { Delay if } \theta \in\left[0, \theta_{1}\right) \text { or } a_{1 M}=\{\text { announce }\}
\end{array}\right. \\
\sigma_{2 B}\left(\theta, h, p_{2}\right) & =\left\{\begin{array}{l}
\text { Buy if } \theta \in\left[\theta_{2}, \theta_{1}\right] \\
\text { Do Not Buy, if } \theta \in\left[0, \theta_{2}\right)
\end{array}\right.
\end{aligned}
$$

In what follows, we will analyze the equilibrium strategies. Given condition 1 and 2 of our equilibrium, we should start solving the problem backwards. The quality and $\theta_{1}$ will be revealed in the second period, then consumers will buy if their payoff is non-negative; that is, the second period buyers are $Y=\left\{\theta \geq \theta_{2} \mid \theta_{2} \gamma_{i}-p_{2}^{i}=0\right.$ and $a_{1 B}(\theta)=$ Delay $\}$. The $\theta_{2}$ consumer is the threshold agent that is just indifferent between buying and not buying in the second period. The monopolist's maximization problem in this period gives the following prices and the second period profits, $\Pi_{2}\left(\gamma_{i}\right)$ :

$$
\max _{p_{2}^{i}} p_{2}^{i}\left(\theta_{1}-\theta_{2}\right) \text { s.t. } \theta_{2} \gamma_{i}-p_{2}^{i}=0 \Rightarrow p_{2}^{i}=\frac{\gamma_{i} \theta_{1}}{2} \Rightarrow \Pi_{2}\left(\gamma_{i}\right)=\gamma_{i}\left(\frac{\theta_{1}}{2}\right)^{2}
$$

Now moving back to the customers' equilibrium strategies in period 1, each consumer will form a belief $\mu_{1 B}$ that the good is high quality after observing the first period price, $p_{1}$. The threshold agent $\theta_{1}$ will receive the following payoff from buying:

$$
(1+\delta) \theta_{1}\left[\mu_{1 B}+\left(1-\mu_{1 B}\right) \gamma_{l}\right]-p_{1}^{i}
$$

If she delays buying the good, she will receive a (discounted expected) payoff of

$$
\delta\left[\mu_{1 B}\left(\theta_{1}-p_{2}^{H}\right)+\left(1-\mu_{1 B}\right)\left(\theta_{1} \gamma_{l}-p_{2}^{L}\right)\right]
$$

where $p_{2}^{j}$ is the second period price when the revealed quality is $j=H, L$. By equating these two terms, we can calculate the set of first period buyers $V=\left[\theta_{1}, 1\right]$ and the set of second period buyers $Y=\left[\theta_{2}, \theta_{1}\right)$. Specifically, by plugging in for the second period price and solving for the indifference condition gives us:

$$
\theta_{1}\left(p_{1}^{i}, \mu_{1 B}\right)=\frac{2 p_{1}^{i}}{(2+\delta)\left[\mu_{1 B}+\left(1-\mu_{1 B}\right) \gamma_{l}\right]}
$$


Now, we can write the monopolist's profit (payoff) as a function of $p_{1}^{i}$ and $\mu_{1 B}$ with the help of equation 1 :

$$
V_{\gamma_{i}}\left(p_{1}^{i}, \mu_{1 B}\right)=p_{1}^{i}\left(1-\theta_{1}\left(p_{1}^{i}, \mu_{1 B}\right)\right)+\delta \gamma_{i}\left(\frac{\theta_{1}\left(p_{1}^{i}, \mu_{1 B}\right)}{2}\right)^{2}
$$

\subsection{Separating Equilibrium: Both Types Sell in Both Periods}

In what follows, we will give different types of separating equilibria. In the separating equilibrium given in Proposition 1, consumers will be convinced of high quality if they see a very high price in the first period. The low type monopolist chooses its profit maximizing price rather than imitating the high-type. The high type will be better off by choosing the equilibrium price rather than waiting/announcing and selling only in the second period, or posing as low type in the first period. In this equilibrium, prices will decline for both types in the second period. Therefore, the result is different than Bagwell and Riordan (1991) in the sense that low type also chooses high and declining prices.

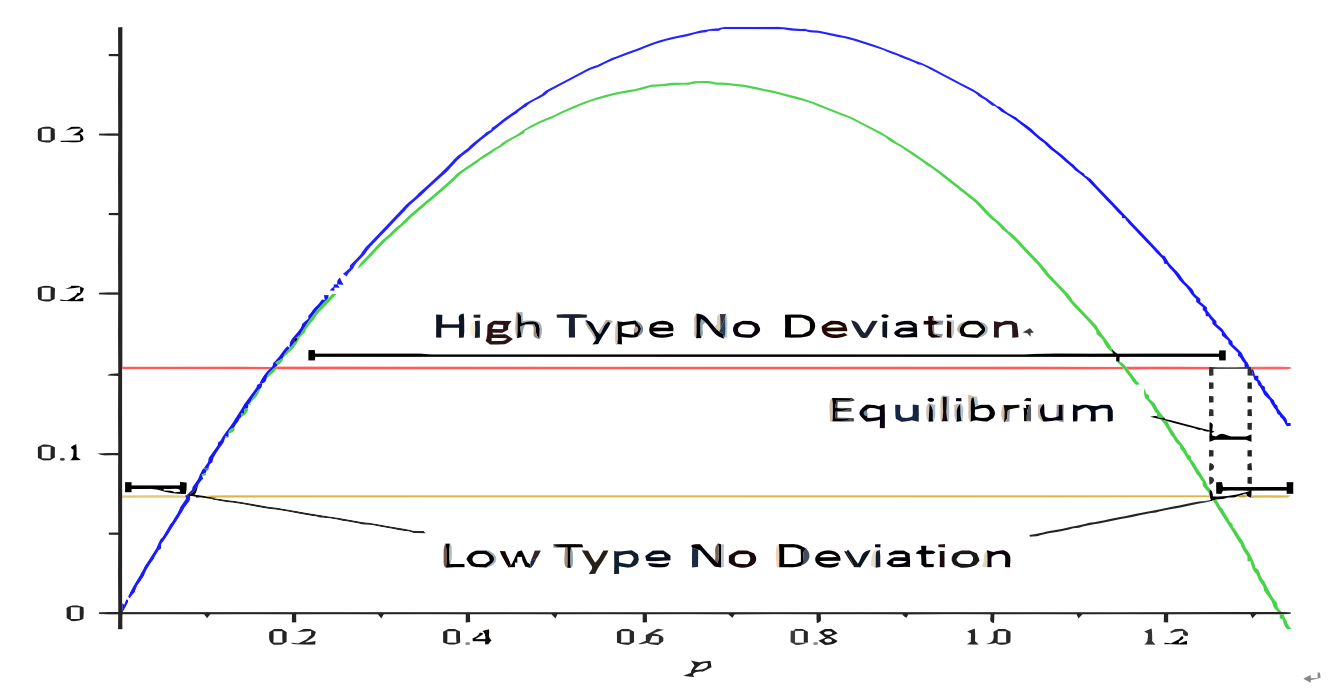

Figure 2: A separation equilibrium example when high type separates itself by choosing $p_{1} \in\{1.253,1.295\}$. The lines are equilibrium and deviation payoffs for high and low types. While it is not shown on the graph, waiting to sell in the second period is not profitable when $0.34<p_{1}<1.3$. 
Proposition 1 Assume that $\gamma_{l}>\frac{\delta}{\delta+4}$. There are separating equilibria in which both low and high type monopolist sell in both periods. There is an equilibrium that satisfies the Intuitive Criterion.

The high type sets a (very) high price in the first period and sells only to a small subset of consumers, despite the fact that consumers correctly infer that this is a high quality product. The low type cannot mimic this strategy of setting a high price in the first period since selling only a small subset of consumers in the first period (and, as a result, having a low total sales in both periods) is not profitable. Instead, it wants to sell as much as possible both in the first and the second period. This can be done by setting a low enough price in the first period. As $\gamma_{l}$ gets smaller, the low type's profit decreases in a separating equilibrium. If it gets too small, then the low type would deviate by choosing the high type monopolists's price since this gives him a higher profit. This is why we need the condition $\gamma_{l}>\frac{\delta}{\delta+4}$.

Figure 3 shows an example of such an equilibrium. It shows the price range in which the high-type and the low-type will not deviate. When the price is in the overlapping area, no types will deviate and hence we have a separating equilibrium. The high type should also not deviate to "waiting and only selling in the second period" equilibrium (this range is not shown in the figure).

\subsection{Pooling Equilibrium and Introductory Low Price}

In Proposition 2 below, we explain pooling equilibria.

Proposition 2 There are pooling equilibria in which both types choose the same price to sell in the first period. When $\gamma_{l}=0$, there is an equilibrium that satisfies the Intuitive Criterion.

Let us concentrate on the equilibrium that satisfies the Intuitive Criterion. Since $\gamma_{l}=0$, if the low type deviates, it cannot sell any product and end up with zero profits. Therefore, the low type does not deviate. The high type has no incentive to deviate to be seen as low type but may have an incentive to deviate to waiting. When consumers believe that a firm is a high type with probability $\alpha$ if $p_{1}$ in the range $\frac{\delta(2+\delta) \alpha}{4(2+\delta) \alpha-2 \delta}<p_{1}<\frac{(2+\delta) \alpha}{2}$, then deviation to waiting is not profitable, and a pooling equilibrium can be sustained. 
Given equation 2, we know that $\frac{d \theta_{1}}{d \alpha}<0$. In other words, when consumers are more pessimistic, more of them strategically delay their buying to the second period. By equation 1 , we know that $\frac{d p_{2}}{d \alpha}=\frac{\gamma_{i}}{2} \frac{d \theta_{1}}{d \alpha}<0$. That is, the more strategically delay their buying to the second period, the higher the second period price of the monopolist. Not surprisingly, the high type increases its price more, and this inevitably deters strategic delay incentives. However, we admit that this may be due to modelling assumptions since as $\theta_{1}$ increases (due to a lower $\alpha$ ), the remaining consumers have a higher willingness to pay (compared to a lower $\left.\theta_{1}\right)$. Hence, both type of monopolist can and do charge a higher price.

Our main interest is to analyze when the firm uses the introductory low price strategy and when they use the cream skimming strategy (that is, lower the prices in the second period). The next proposition finds sufficient conditions for these strategies for a given equilibrium. We note that this sufficient condition is exactly the same for all equilibria of Proposition 2. The reason is that the consumers' (off and on path) beliefs determine the first period price but the monopolist's profit maximization problem determines the second period price.

Proposition 3 For any given pooling equilibrium: a) (introductory low price) the high-type firm will set a higher second period price if $\delta<\frac{1-2\left(\alpha+\gamma_{l}-\alpha \gamma_{l}\right)}{\left(\alpha+\gamma_{l}-\alpha \gamma_{l}\right)}$. b) (cream-skimming) The high-type firm will set a lower second period price if $\delta>\frac{1-2\left(\alpha+\gamma_{l}-\alpha \gamma_{l}\right)}{\left(\alpha+\gamma_{l}-\alpha \gamma_{l}\right)}$.

As $p_{2}$ is higher in equilibrium, the cost of delaying strategically will be higher for consumers. In addition, if the consumers are too pessimistic about the quality, firms are more likely to offer introductory low prices. The high-type monopolist sells to "the high willingness to pay" consumers in the first period. In a pure private value durable good model, the monopolist has no chance but to lower the price in the second period to sell to the remaining/residual lower types. In our model, the remaining lower willingness to pay consumers, in the second period, learn that the quality is much higher than their expectations. Hence, their total willingness to pay increases. This will enable the monopolist to charge a higher price. This result differs from the intertemporal price discrimination literature (such as Stokey (1979), Landsberger and Meilijison (1985), Tirole (1989)) which shows that the price must decrease in all periods. Once the uncertainty is resolved (and if we had more 
than two periods), we are essentially back in the pure private value model and the price will decrease starting from period three onwards. Introducing uncertainty on quality is the key factor that differentiates our results from the rest of the literature. ${ }^{11}$

In Shapiro (1983), myopic consumers have point estimates of the quality (biased expectations). If their estimate is lower than actual quality, the firm offers a low introductory price so that consumers can pay higher prices in repeat purchases. Since consumers are myopic, they do not have the price expectation or strategic delay incentives that the consumers in our model have.

Corollary 4 Let $\gamma_{l}=0$. a) If $\alpha<\frac{1}{3}$, the high type will set a higher second period price. b) If $\alpha>\frac{1}{2}$ then the high type will set a lower second period price.

In the proofs, we show that only when $\gamma_{l}=0$, then the pooling equilibrium satisfies the intuitive criterion. In this case, using proposition 3 , the condition for offering introductory low price becomes $\delta<\frac{1-2 \alpha}{\alpha}$. If $\alpha \leq \frac{1}{3}$, this condition is always satisfied; hence, the high type monopolist will always offer introductory low price. Since consumers are pessimistic about the quality, the high type monopolist has to offer a very low price in the first period (and even then relatively a small percentage of consumers buy the product in the first period). When the quality is revealed, consumers are willing to pay a higher price for the high quality good.

In the following example, for $\gamma_{l}>0$, we give a parameter range in which the pooling equilibrium exists while neither separating nor waiting equilibria exists.

Example 5 Let $\mu_{1 B}=\delta=0.4$ and $\gamma_{l}=0$. Since $\gamma_{l}=0$, there cannot be any separating equilibrium (in which there is positive sale in the first period). Low type will always mimic the high type to guarantee a positive profit rather than receiving zero separating equilibrium profit. In our pooling equilibrium, consumers will believe that any firm choosing $p_{1}=0.4$

\footnotetext{
${ }^{11}$ There are two other papers that discuss Coasian dynamics with agents consuming two goods unlike our paper. Koh (2006) shows that a durable good monopolist who commits to its pricing path and faces infinitely lived heterogeneous agents consuming both perishable and durable good may offer low prices initially. His results depend on the consumption of perishable good in each period. Lee (2003) shows that Coasian dynamics may lead to the sale of degraded goods that are as costly as producing high-quality goods. Selling de-graded goods mitigate consumers' waiting incentives.
} 
is a high type with probability 0.4 . In the proof of pooling equilibrium, we show that for any $p_{1} \in\{0.12,0.48\}$ (with belief $\mu_{1 B}=0.4$ ) and $\gamma_{l}<\frac{\delta}{2+\delta}$, waiting equilibrium payoff is lower than the pooling equilibrium payoff for the high type and hence we have a pooling equilibrium. ${ }^{12}$ In such an equilibrium, the second period price will be $p_{2} \simeq 0.468$ which is greater than the first period price.

\subsection{Separating Equilibrium: High-Type Waits}

In proposition 6 below, we give a waiting equilibrium. If the low type monopolist's quality is too low (and consumers believe that any firm waiting is a high type), the high-type finds it profitable to wait for the second period (i.e., announce) rather than selling as a low type in the first period. The low type chooses its profit maximizing price in the first period.

Proposition 6 (Waiting equilibrium) Suppose that $\gamma_{l}<\frac{\delta}{2+\delta}$ holds. There are separating equilibria in which low type sells in the first period and the high type announces the product launch date in the first period and waits to sell in the second period. If $\gamma_{l}=0$, the equilibrium satisfies the Intuitive Criterion.

If $\gamma_{l}=0$, then the low type would like to mimic the high type's price in the first period price. The high type responds by waiting to sell in the first period, and hence, a "waiting equilibrium" is sustained.

A monopolist may signal its quality through announcing the launch date of its product although its product is ready at the time. Hence, this is not a "vaporware" example (unlike Dranove and Gandal (2003)) since the product is delivered on its launch date. In order to have such a waiting equilibrium, $\gamma_{l}$ should be low enough so that the high type will have a great incentive to distinguish itself from the low type (depending on the off-path equilibrium beliefs, it would not choose to sell in the first period). Also, as discount factor increases, it is more likely to have such an equilibrium since waiting is less costly.

When $\gamma_{l}$ is zero, the intuitive criterion is satisfied since any deviation by the high type will be followed by the low type who receives the zero payoff in the waiting equilibrium. In

\footnotetext{
${ }^{12}$ We impose the off-path equilibrium belief that for any other $p_{1}$, consumers believe that this is a low type with probability 1 .
} 
other words, there is no $p_{1}$ choice by the high type that is equilibrium dominated for the low type.

\section{$3 \quad$ When only $\beta$ fraction of agents learn the true quality in the second period}

In this section, we will show that we can construct the "waiting equilibrium" when only a $\beta$ fraction of agents learn the true quality in the second period.

We assume that the monopolist cannot distinguish the informed and uninformed consumers in the second period so price discrimination is not possible.

The second period profit maximization function of the $\gamma_{i}>0$ type monopolist is as follows:

$$
\max _{p_{2}^{i}} p_{2}^{i}\left[\beta\left(\theta_{1}-\frac{p_{2}^{i}}{\gamma_{i}}\right)+(1-\beta)\left(\theta_{1}-\frac{p_{2}^{i}}{\mu_{2 B}+\left(1-\mu_{2 B}\right) \gamma_{l}}\right)\right]
$$

since informed agents buy the product as long as their type satisfies $\theta \gamma_{i}-p_{2}^{i} \geq 0$ and uninformed agents buy as long as their type satisfies $\theta\left(\mu_{2 B}+\left(1-\mu_{2 B}\right) \gamma_{l}\right)-p_{2}^{i} \geq 0$. The uninformed agents use the expected value of $\gamma_{i}$ given their second period beliefs $\mu_{2 B}$.

If we differentiate this function with respect to $p_{2}$ and set it to zero, we can get the profit maximizing second period price $p_{2}^{i}$ as a function of $\theta_{1}$ which is

$$
p_{2}^{i}=\frac{\theta_{1} \gamma_{i}\left(\mu_{2 B}+\gamma_{l}-\gamma_{l} \mu_{2 B}\right)}{2\left[\left(\beta\left(\mu_{2 B}+\gamma_{l}-\gamma_{l} \mu_{2 B}-\gamma_{i}\right)+\gamma_{i}\right)\right]}
$$

Then, given $\theta_{1}$, the profit maximization of the monopolist is:

$$
\max _{p_{1}} p_{1}\left(1-\theta_{1}\right)+\delta p_{2}^{i}\left[\beta\left(\theta_{1}-\frac{p_{2}^{i}}{\gamma_{i}}\right)+(1-\beta)\left(\theta_{1}-\frac{p_{2}}{\mu_{2 B}+\left(1-\mu_{2 B}\right) \gamma_{l}}\right)\right] \quad \text { s.t } \quad \text { eq } 2 \text { and eq } 5
$$

To construct a waiting equilibrium, let us suppose that consumers believe any firm who do not wait/announce is a low type; that is, $\mu_{1 B}\left(a_{1 M}=p 1\right)=0$. First, let us find the range in which the low type monopolist will not imitate the high type who is waiting. The low type monopolist's profit in the waiting equilibrium can be found from the equation 6 when $\mu_{2 B}=0$ 
since consumers can detect the type in a separating equilibrium. ${ }^{13}$ We need to calculate $\theta_{1}$. Given the beliefs, we can calculate it from the equation $(1+\delta) \theta_{1} \gamma_{l}-p_{1}=\delta\left[\theta_{1} \gamma_{l}-p_{2}\right]$. By using equation 5 , we derive that $\theta_{1}=\frac{2 p_{1}}{(2+\delta) \gamma_{l}}$. Note that $\beta$ has no role since consumers know the type with certainty in a separating equilibrium. In this equilibrium, the profit of low type will be the same as in equation 6 :

$$
\text { Low Type Profit in Waiting } E q=\frac{\gamma_{l}(2+\delta)^{2}}{4(4+\delta)}
$$

If the low type deviates to waiting, then we can calculate the deviation profit by setting $\mu_{2 B}(., \tau=U)=1$ but $\mu_{2 B}(., \tau=I)=0$. In this equilibrium, since low type does not sell anything in the first period, we have $\theta_{1}=1$. By using equation 6 , we get the deviation profit which is:

$$
\text { Low Type Deviation Profit }=\frac{\delta \gamma_{l}}{4\left[\left(1-\gamma_{l}\right) \beta+\gamma_{l}\right]}
$$

If the equilibrium profit is higher than the deviation profit, we know that low type would not deviate to waiting. This condition is

$$
\frac{\gamma_{l}(2+\delta)^{2}}{4(4+\delta)} \geq \frac{\delta \gamma_{l}}{4\left[\left(1-\gamma_{l}\right) \beta+\gamma_{l}\right]} \Leftrightarrow \gamma_{l} \geq \frac{(4+\delta) \delta-\beta(2+\delta)^{2}}{(1-\beta)(2+\delta)^{2}}
$$

If $\gamma_{l}$ is big enough, then the low type does not have to deviate to waiting. Also, as $\beta$ approaches to 1 , the numerator becomes negative and the condition is always satisfied. The more informed the consumers are, the more likely to have a waiting equilibrium in which high type waits but the low type sells in the first period. This is an intuitive result.

Now, we will derive the condition that the high type does not deviate.

It is easy to see that the profit of the high type in a waiting equilibrium is the same as in the main model which is $\frac{\delta}{4}$.

If the high type deviates to selling in the first period, then the beliefs will be $\mu_{1 B}=0$, $\mu_{2 B}(., \tau=I)=1$, and $\mu_{2 B}(., \tau=U)=0$. Then, the threshold agent $\theta_{1}$ can be found from

\footnotetext{
${ }^{13}$ Specifically, $\mu_{2 B}(., \tau=I)=\mu_{2 B}(., \tau=U)=0$. That is, both informed and uninformed consumers know that this is a low type since this is a separating equilibrium.
} 
the equation $(1+\delta) \theta_{1} \gamma_{l}-p_{1}=\delta\left(\theta_{1} \gamma_{l}-p_{2}\right)$. By using this, and equation 6 , we can calculate the deviation profit of the hight type: ${ }^{14}$

$$
\frac{(2+\delta)^{2} \gamma_{l}\left(1-\beta\left(1-\gamma_{l}\right)\right)}{4\left[4-(4 \beta+2 \delta \beta)\left(1-\gamma_{l}\right)+\delta\right]}
$$

Hence, the high type does not deviate if $\frac{\delta}{4}-\frac{(2+\delta)^{2} \gamma_{l}\left(1-\beta\left(1-\gamma_{l}\right)\right)}{4\left[4-(4 \beta+2 \delta \beta)\left(1-\gamma_{l}\right)+\delta\right]}>0$ holds for some parameter range of $\left(\beta, \gamma_{l}, \delta\right)$. Intuitively, we expect that as $\beta \rightarrow 1$, there are waiting equilibria. To show one equilibrium, we set $\gamma_{l}=0.25$. Then, by using MAPLE, we showed that when $\beta=\delta=0.9$, there is a waiting equilibrium since both the low type and the high type would not deviate. Of course, by continuity, one can see that there are infinitely many waiting equilibrium when we chose parameters close to the set ones.

\section{Efficiency Loss and Welfare in Waiting Equilibrium Case}

In this section, we will calculate the efficiency loss for the equilibrium that satisfies the intuitive criterion (i.e., $\gamma_{l}=0$ ) for the waiting equilibrium. In the Appendix, we analyze the welfare loss for separating equilibrium case.

We will calculate the efficiency loss of waiting equilibrium when $\gamma_{l}=0$ compared to the perfect information case. The low type does not produce anything neither in the perfect information case nor in the waiting equilibrium so there is no efficiency loss when the monopolist is low type of $\gamma_{l}=0$.

The high type will only sell in the second period and from equation 1, one can easily see that $p_{2}=\theta_{2}=\frac{1}{2}$. Therefore, welfare under the waiting equilibrium, $W_{w}$, given that $\alpha$ is the probability of having the high type, is:

$$
W_{w}=\alpha \delta\left(\frac{1}{4}+\frac{1}{8}\right)=\alpha \delta \frac{3}{8}
$$

The first term in the parenthesis is the profit and the second term is the consumer surplus which can be calculated from $\delta \int_{\frac{1}{2}}^{1}\left(\theta-\frac{1}{2}\right) d \theta$.

\footnotetext{
${ }^{14}$ If $\beta=1$, we get the same profit as in the previous section which is $\frac{(2+\delta)^{2} \gamma_{l}^{2}}{4\left[4 \gamma_{l}+2 \delta \gamma_{l}-\delta\right]}$
} 
The welfare under the perfect information case, $W_{p}$ is as follows. In this case, $\mu_{1 B}=1$ since there is perfect information. A quick calculation shows that second period maximization problem gives $p_{2}=\theta_{2}=\frac{\theta_{1}}{2}$. Since $\theta_{1}=\frac{2 p_{1}}{2+\delta}$ (from equation 2 when $\mu_{1 B}=1$ ), the profit maximization problem becomes:

$$
\max _{p_{1}} p_{1}\left(1-\frac{2 p_{1}}{2+\delta}\right)+\frac{\delta}{4}\left(\frac{2 p_{1}}{(2+\delta)}\right)^{2}
$$

When we differentiate, we find the first order conditions:

$$
1-\frac{4 p_{1}}{2+\delta}+\frac{\delta 2 p_{1}}{(2+\delta)^{2}}=0
$$

This gives $p_{1}=\frac{(2+\delta)^{2}}{2(4+\delta)}$ and $\theta_{1}=\frac{2+\delta}{4+\delta}$. We can calculate the profit of high type (From equation 3):

$$
V_{\gamma_{h}}\left(p_{1}=\frac{(2+\delta)^{2}}{2(4+\delta)}, \mu_{1 B}=1\right)=\frac{(2+\delta)^{2}}{4(4+\delta)}
$$

The consumer surplus is:

$$
\begin{aligned}
& \int_{\theta_{1}=\frac{2+\delta}{(4+\delta)}}^{1}\left(\theta-\frac{(2+\delta)^{2}}{2(4+\delta)}\right) d \theta+\delta \int_{\theta_{1}=\frac{2+\delta}{2(4+\delta)}}^{\theta_{2}=\frac{2+\delta}{(4+\delta)}}\left(\theta-\frac{2+\delta}{2(4+\delta)}\right) d \theta \\
& =\left[\frac{1}{2}-\frac{(2+\delta)^{2}}{2(4+\delta)^{2}}-\frac{(2+\delta)^{2}}{2(4+\delta)}+\frac{(2+\delta)^{3}}{2(4+\delta)^{2}}\right]+\delta\left[\frac{(2+\delta)^{2}}{8(4+\delta)^{2}}\right]
\end{aligned}
$$

where the first bracket parenthesis is the first period consumer surplus, the second one is the second period consumer surplus (after simplifications). We summarize the efficiency loss and its derivative with respect to $\delta$ in the following proposition:

Proposition 7 The efficiency loss in waiting equilibrium is:

$$
E L_{w}=W_{p}-W_{w}=\frac{\alpha}{2(4+\delta)^{2}}[(3+\delta)(4-3 \delta)]
$$

Efficiency loss decreases as agents become more patient:

$$
\frac{d\left(W_{p}-W_{w}\right)}{d \delta}=\frac{\alpha(-44-19 \delta)}{2(4+\delta)^{3}}<0
$$


As $\delta$ increases, efficiency loss decreases. Increase in $\delta$ has two (counter) effects on $W_{p}$. The first effect causes price to increase. This makes fewer agents buy the good. Consumer surplus decreases; hence, this lowers welfare. However, the second effect causes profits to increase. The second effect dominates and $W_{p}$ increases. It is easy to see that $W_{w}$ increases with $\delta$. It must be the case that $W_{w}$ increases more than $W_{p}$; therefore, the efficiency loss decreases.

\section{Discussion and Conclusion}

If we extend the model to three or more periods, we will find that the price will decrease from the third period onwards. Since the uncertain common value will be learned in the second period, this model will essentially be a pure private value durable good model. If the monopolist wants to sell to the residual lower willingness to pay type consumers in the third period, it has to decrease the price (as in Stokey (1979) or Landsberger and Meilijson (1985)).

The model produces many pooling equilibria; however, we show that the sufficient condition to offer introductory low prices or use cream-skimming strategies is the same for any given pooling equilibrium. In our pooling equilibria, the beliefs determine the first period price but the monopolist's actual profit maximization motive determines the second period price. As long as the beliefs of consumers are known, the equilibrium that will be selected is known by all parties; that is, there is no coordination problem. However, we do not attempt to explain how these beliefs are formed.

We have used uniform distribution. We believe that using a general distribution would not bring any new insights than the current paper but only complicate the model.

\subsection{Conclusion}

We show how a monopolist will price its good when consumers do not know the quality but will learn it in the second period. This leads to strategic delay and price expectations on the part of consumers. The monopolist will take these into account and price its good dynamically. 
One of our main contributions is showing that the high type monopolist can signal its quality by announcing a future launch date even though the product is ready to sell today. Microsoft's launching of Windows 7 may be an example to this strategy. ${ }^{15}$

Signalling creates a welfare loss. We show that as agents become more patient or the low type's quality increases, this loss decreases.

One contribution of our paper is to show that consumers may delay their buying to learn quality. This is in contrast with Coasian dynamics under a model in which there is no learning.

\section{Appendix}

Definition 1 (Perfect Bayesian Equilibrium): A profile of (pure) strategies $\sigma=$ $\left(\sigma_{1 B}, \sigma_{2 B}, \sigma_{1 M}, \sigma_{2 M}\right)$ (where $\sigma_{1 M}: \Psi \mapsto A_{1 M}$ and $\sigma_{2 M}: H \times \Psi \mapsto A_{2 M}$ and $\sigma_{1 B}: \Theta \times A_{1 M} \mapsto$ $A_{1 B}$, and $\sigma_{2 B}: H \times A_{2 M} \times \Theta \mapsto A_{2 B}$.) and the belief system $\mu=\left(\mu_{1 B}, \mu_{2 B}\right)$ (where $\mu_{1 B}: A_{1 M} \mapsto[0,1]$, and $\mu_{2 B}: H \times A_{2 M} \times\{I, U\} \mapsto[0,1]$ is a Perfect Bayesian Equilibrium if

Condition 1. For any $\gamma_{i}$ and $h, \sigma_{2 M}\left(\gamma_{i}, h\right)$ solves

$\max _{p_{2}} p_{2}\left[\int_{\sigma_{2 B}\left(\theta, h, p_{2}, \tau=I\right)=B u y} d \theta+\int_{\sigma_{2 B}\left(\theta, h, p_{2}, \tau=U\right)=B u y} d \theta\right]$

Condition 2. For any $\theta, \tau, h$, and $p_{2}, \sigma_{2 B}\left(\theta, \tau, h, p_{2}\right)=$ Buy iff $\theta\left[\mu_{2 B}\left(h, p_{2}, \tau\right)+(1-\right.$ $\left.\mu_{2 B}\left(h, p_{2}, \tau\right) \gamma_{l}\right] \geq p_{2}$.

Condition 3. For any $\gamma_{i}, \sigma_{1 M}\left(\gamma_{i}\right)$ solves

$$
\begin{aligned}
& \max _{a_{1 M}}\left\{\delta \sigma_{2 M}\left(\gamma_{i}, h\left(a_{1 B}, a_{1 M}=\text { announce, } \gamma_{i}\right)\right)\right. \int_{\sigma_{2 B}\left(\theta, \tau, h\left(., a_{1 M}=\text { announce }\right), \sigma_{2 M}\left(\gamma_{i}, h\left(., a_{1 M}=\text { announce }\right)\right)\right)=\text { Buy }} \int d \tau d \theta \\
&\left.\max _{p_{1}} p_{1} \int_{\sigma_{1 B}\left(\theta, p_{1}\right)=B u y} d \theta+\delta \sigma_{2 M}\left(\gamma_{i}, h\left(a_{1 B}, p_{1}, \gamma_{i}\right)\right) \int_{\sigma_{2 B}\left(\theta, \tau, h\left(., p_{1}\right), \sigma_{2 M}\left(\gamma_{i}, h\left(., p_{1}\right)\right)\right)=\text { Buy }} \int d \tau d \theta\right\}
\end{aligned}
$$

where $h\left(a_{1 B}, a_{1 M}, \gamma_{i}\right)$ is the history that arises when the monopolist offers price $p_{1}$ or chooses announce, the buyers choose their actions according to $a_{1 B}$ in period 1 and the quality $\gamma_{i}$ is revealed but only learned by the informed buyers $(\tau=I)$

\footnotetext{
${ }^{15}$ We emphasize that our paper is a theoretical exercise and there may be other reasons for this waiting.
} 
Condition 4. For any $\theta$ and $p_{1}, \sigma_{1 B}\left(\theta, p_{1}\right)=$ Buy if and only if:

$$
\begin{array}{r}
(1+\delta) \theta\left(\mu_{1 B}\left(p_{1}\right)+\left(1-\mu_{1 B}\left(p_{1}\right) \gamma_{l}\right)-p_{1} \geq\right. \\
\delta\left[\mu_{1 B}\left(p_{1}\right)\left(\theta-\sigma_{2 M}\left(\gamma_{h}, h^{\prime}\right)\right)+\left(1-\mu_{1 B}\left(p_{1}\right)\right)\left(\theta \gamma_{l}-\sigma_{2 M}\left(\gamma_{l}, h^{\prime}\right)\right)\right]
\end{array}
$$

where $h^{\prime}=h\left(\left\{\sigma_{1 B}\left(\theta^{\prime}, p_{1}\right)\right\}_{\theta^{\prime} \neq \theta}, a_{1 B}(\theta)=\right.$ Delay, $\left.p_{1}, \gamma_{i}\right)$ is the history that arises when in period 1, the type $\theta$ consumer delays his decision while the monopolist offers price $p_{1}$ and other consumers choose their actions according to $\sigma_{1 B}$, and the revealed quality is $\gamma_{i}$.

For any $\theta, \sigma_{1 B}(\theta$, announce $)=$ Delay.

Condition 5. Consumers update their beliefs using Bayesian rule whenever possible. In the second period, since the quality is revealed to informed consumers, we have $\mu_{2 B}\left(h^{\prime}, \sigma_{2 M}, \tau=\right.$ $I)=1$ if $\gamma_{i}=1$, and $\mu_{2 B}\left(h^{\prime}, \sigma_{2 M}, \tau=I\right)=0$ if $\gamma_{i}=\gamma_{l}$.

\section{Proof of Proposition 1}

We will show that if consumers believe $p_{1} \in\left\{\right.$ rootlow $2, \min \left[\right.$ roothigh $\left.\left.2, \frac{2+\delta}{2}\right]\right\}$ comes from a high type, then there will be separating equilibria. We will give the explanation of rootlow 2 and roothigh 2 below.

We have already calculated the threshold agent $\theta_{1}$ and profit $V_{\gamma}\left(p_{1}, \mu_{1 B}\right)$ for a given $\mu_{1 B}$ and $p_{1}$ in the text in equations 2 and 3 . They were;

$$
\begin{gathered}
\theta_{1}\left(p_{1}, \mu_{1 B}\right)=\frac{2 p_{1}}{(2+\delta)\left[\mu_{1 B}+\left(1-\mu_{1 B}\right) \gamma_{l}\right]} \\
V_{\gamma_{i}}\left(p_{1}, \mu_{1 B}\right)=p_{1}\left(1-\theta_{1}\left(p_{1}, \mu_{1 B}\right)\right)+\delta \gamma_{i}\left(\frac{\theta_{1}\left(p_{1}, \mu_{1 B}\right)}{2}\right)^{2}
\end{gathered}
$$

First, we will find the price range that the low type monopolist will not deviate. In a separating equilibrium, the low type monopolist will maximize its profits as follows:

$\max _{p_{1}} V_{\gamma_{l}}\left(p_{1}, 0\right)=p_{1}\left(1-\theta_{1}\left(p_{1}, 0\right)\right)+\delta \gamma_{l}\left(\frac{\theta_{1}\left(p_{1}, 0\right)}{2}\right)^{2}$.

Solving this maximization problem yields $p_{1}=\frac{(2+\delta)^{2} \gamma_{l}}{2(4+\delta)}$ which in turn yields $\theta_{1}=\frac{2+\delta}{4+\delta}$. Thus, the profit of low quality type in a separating equilibrium is given by:

$$
\pi_{\text {SepLow }}=V_{\gamma_{l}}\left(p_{1}=\frac{(2+\delta)^{2} \gamma_{l}}{2(4+\delta)}, \mu_{1 B}=0\right)=\frac{\gamma_{l}(2+\delta)^{2}}{4(4+\delta)}
$$


We now calculate the low type producer's deviation profits if it deviates to some price range so that consumers believe he is a high type. This deviation profit is:

$$
\pi_{\text {SepLowDev }}=V_{\gamma_{l}}\left(p_{1}, \mu_{1 B}=1\right)=p_{1}\left(1-\frac{2 p_{1}}{(2+\delta)}\right)+\frac{\delta \gamma_{l} p_{1}^{2}}{(2+\delta)^{2}}
$$

To compare the profits of the separating equilibrium with the profits of the deviation, we subtract the deviation profits from the separating equilibrium profits and set the resulting function equal to 0. i.e. $\pi_{S e p L o w}-\pi_{\text {SepLowDev }}=\frac{\gamma_{l}(2+\delta)^{2}}{4(4+\delta)}-\left[p\left(1-\frac{2 p}{(2+\delta)}\right)+\frac{\delta \gamma_{l} p^{2}}{(2+\delta)^{2}}\right]=0=f(p)$.

Since $f$ and $\pi_{\text {SepLowDev }}$ is a polynomial of degree two, we can find at most two roots, and later we will show that there are exactly two roots. These roots will be positive since $\pi_{\text {SepLowDev }}(p=0)=0, \pi_{\text {SepLowDev }}$ is increasing at 0 , concave (because $f^{\prime \prime}=\pi_{\text {SepLowDev }}^{\prime \prime}=$ $\frac{\delta\left(-4+\gamma_{l}\right)-4}{(2+\delta)^{2}}<0$ ), and $\pi_{\text {SepLow }}>0$ for any positive $\gamma_{l}$ (see figure 3 ). For any price p lower than the smallest root and any price p greater than the biggest root, the profit from deviating is less than the profit from the separating equilibrium. We calculate the roots of this function; rootlow 1 is the smallest root, and rootlow 2 is the greatest root. In the equations below, the term inside the square roots are positive; hence, there are exactly two roots.

$$
\begin{aligned}
& \text { rootlow } 1=\frac{\left[(2+\delta)^{2}\left[4+\delta-\sqrt{(4+\delta)\left(1-\gamma_{l}\right)\left[\delta\left(1-\gamma_{l}\right)+4\right)}\right]\right.}{2(4+\delta)\left(\delta\left(2-\gamma_{l}\right)+4\right)} \\
& \text { rootlow } 2=\frac{\left[(2+\delta)^{2}\left[4+\delta+\sqrt{(4+\delta)\left(1-\gamma_{l}\right)\left[\delta\left(1-\gamma_{l}\right)+4\right)}\right]\right.}{2(4+\delta)\left(\delta\left(2-\gamma_{l}\right)+4\right)}
\end{aligned}
$$

In what follows, we will calculate the two roots in which the high type monopolist will not deviate if the price is within these two roots.

Let us calculate the high type's profit in a separating equilibrium given $p_{1}$.

$$
\pi_{\text {SepHigh }}=V_{\gamma=1}\left(p_{1}, \mu_{1 B}=1\right)=p_{1}\left(1-\frac{2 p_{1}}{(2+\delta)}\right)+\frac{\delta p_{1}^{2}}{(2+\delta)^{2}}
$$

The profits of the high firm posing as a low firm as a function of $p_{1}$ is given by $V\left(p_{1}, \mu_{1 B}=\right.$ $0, \gamma=1)=p_{1}\left(1-\frac{2 p_{1}}{\gamma l(2+\delta)}\right)+\delta \frac{p_{1}^{2}}{\gamma_{l}^{2}(2+\delta)^{2}}$. If we maximize this function with respect to $p_{1}$, we find price that will maximize the deviation profit, $p_{1}=\frac{\gamma_{l}^{2}(2+\delta)^{2}}{2\left(4 \gamma_{l}+2 \delta \gamma_{l}-\delta\right)}$. Since, we assume that $\gamma_{l}>\frac{\delta}{4+\delta}$, this will guarantee that $p_{1}$ is positive plus the roots below (roothigh1 and roothigh2) exist. 


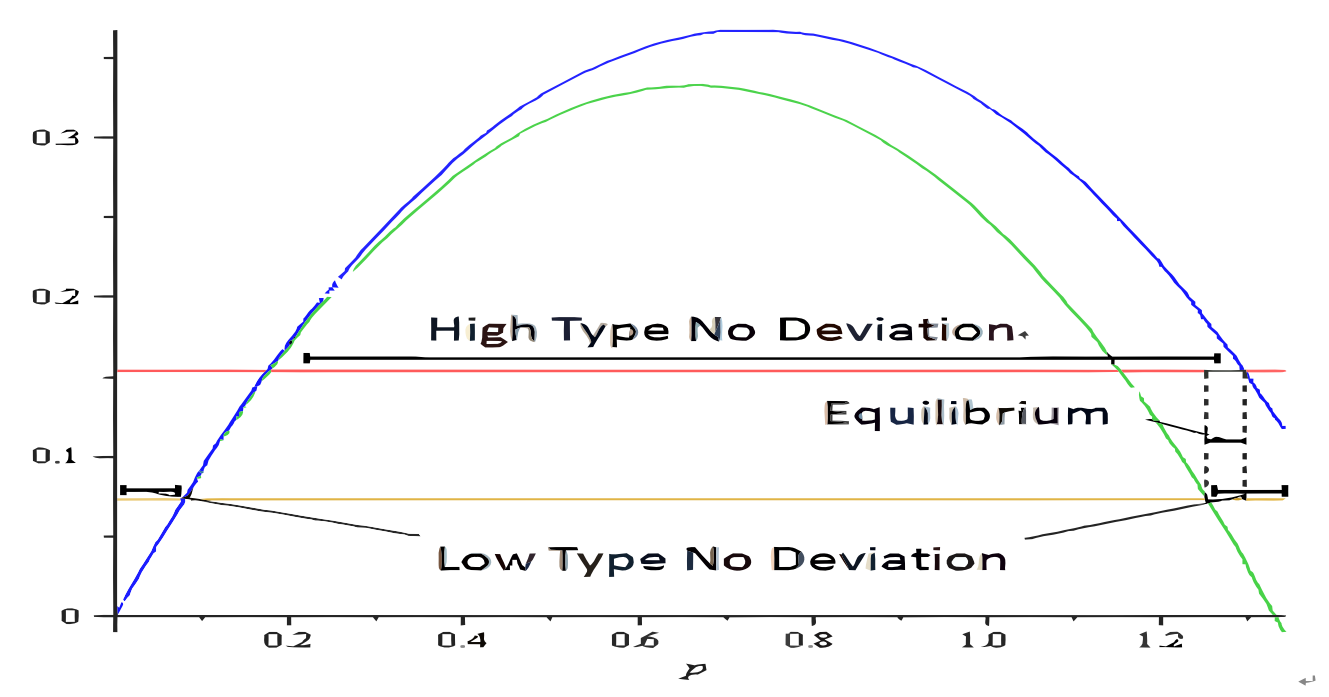

Figure 3: A separation equilibrium example when high type separates itself by choosing $p_{1} \in\{1.253,1.295\}$. The lines are equilibrium and deviation payoffs for high and low types. While it is not shown on the graph, waiting to sell in the second period is not profitable when $0.34<p_{1}<1.3$.

By inserting the expression for $p_{1}$ into the profit function, we get the maximum profit from deviating (and our assumption $\gamma_{l}>\frac{\delta}{4+\delta}$ implies it is always positive):

$$
\pi_{\text {SepHighDev }}=\frac{\gamma_{l}^{2}(2+\delta)^{2}}{4\left(4 \gamma_{l}+2 \delta \gamma_{l}-\delta\right)}
$$

We have to find the range in which a deviation will not occur. By equating the $\pi_{\text {SepHighDev }}$ and $\pi_{\text {SepHigh }}$, we find two roots. The smallest root is roothigh1 and the greatest root is roothigh2:

$$
\begin{aligned}
& \text { roothigh } 1=\frac{(2+\delta)^{2}\left[\left(2 \gamma_{l}(2+\delta)-\delta-\sqrt{\left.\left(1-\gamma_{l}\right)\left(2 \gamma_{l}(2+\delta)-\delta\right)\left(\gamma_{l}(4+\delta)-\delta\right)\right)}\right.\right.}{2(4+\delta)\left[2 \gamma_{l}(2+\delta)-\delta\right]} \\
& \text { roothigh } 2=\frac{(2+\delta)^{2}\left[\left(2 \gamma_{l}(2+\delta)-\delta+\sqrt{\left.\left(1-\gamma_{l}\right)\left(2 \gamma_{l}(2+\delta)-\delta\right)\left(\gamma_{l}(4+\delta)-\delta\right)\right)}\right.\right.}{2(4+\delta)\left[2 \gamma_{l}(2+\delta)-\delta\right]}
\end{aligned}
$$

When $p_{1} \in[$ roothigh 1 , roothigh 2$]$, the high type does not deviate from the separating equilibrium (see figure 3). We should also make sure that announcing/waiting in the first period and selling only in the second period is not profitable for the high type. ${ }^{16}$ The waiting profit of high type is calculated as $\pi_{\text {HighWait }}=\frac{\delta}{4}$. The $\pi_{\text {SepHigh }}-\pi_{\text {HighWait }}=0$ function has two roots:

$$
\frac{\delta(2+\delta)}{(4+\delta)} \text { and } \frac{2+\delta}{2}
$$

\footnotetext{
${ }^{16}$ The low type will never find waiting profitable.
} 
When $p_{1}$ is $\in\left[\frac{\delta(2+\delta)}{(4+\delta)}, \frac{2+\delta}{2}\right]$, waiting will not be profitable.

Therefore, when we have $\max \left\{\frac{\delta(2+\delta)}{(4+\delta)}\right.$, rootlow 2$\}<p_{1}<\min \left\{\right.$ roothigh $\left.2, \frac{2+\delta}{2}\right\},{ }^{17}$ there is a separating equilibrium since neither low type nor the high type deviates. ${ }^{18}$. We can restrict this range further since it is easy to see that $\frac{\delta(2+\delta)}{(4+\delta)}<$ rootlow $2 .{ }^{19}$

In figure 3, we show such a separating equilibrium. When consumers believe that any $p \in\{1.253,1.295\}$ is chosen by the high-type monopolist, all conditions are satisfied, and there is a separating equilibrium.

Now, we will show that there is only one price that satisfies the Intuitive Criterion. First, we assume that $p_{1}=$ rootlow 2 is greater than the high type's profit maximizing price in a perfect information case. In figure 3, we have such a case. The equilibrium that satisfies the Intuitive Criterion is the minimum price in the given range of separating equilibria; that is, $p_{1}=$ rootlow 2 . For any other equilibrium $p_{1}$, the high type monopolist will switch to a slightly lower $p$ in the range (since this will be profit increasing for the high-type by the fact that the payoff function is concave, and as we approach to the profit maximizing price from right, profits will be increasing) but this is equilibrium dominated for the low type monopolist (otherwise this would not be part of separating equilibrium) and hence, consumers should believe that this deviation comes from a high-type monopolist. But then this violates the Intuitive Criterion. When $p_{1}$ is the minimum price in the range, any deviation to a higher price is equilibrium dominated for high type, and any deviation to the right will be better for both low and high types (this would break the separating equilibrium); hence, Intuitive Criterion is satisfied. ${ }^{20}$

Proof of Proposition 2: We will show this for two different cases; 1) $\gamma_{l}<\frac{\delta}{2+\delta}$ and 2) $\gamma_{l}>\frac{\delta}{2+\delta}$.

\footnotetext{
${ }^{17}$ When $\gamma_{l}<\frac{\delta}{2+\delta}, \frac{2+\delta}{2}$ is less than roothigh2.

${ }^{18}$ While we could not prove that rootlow $1<$ roothigh1, all our numeric examples indicated this result. Hence, we do not try to look for other separating equilibria in the range roothigh $1<p_{1}<$ rootlow 1 .

${ }^{19}$ To show that we assume that the square root term in rootlow 2 is zero (otherwise, rootlow 2 will be even a greater number). Then, after some algebraic manipulation, we get $\left.2 \delta^{2}(2-\delta)+8 \delta\right)<8+2 \delta+4 \delta+\delta^{2}$. This is always true since $\delta$ and $\gamma_{l}$ are positive and less than 1 .

${ }^{20}$ If we ever have a separating equilibrium in which $p_{1}=$ rootlow 2 is smaller than the high type's profit maximizing price in a perfect information case, then the profit maximizing price will be the only price that satisfies the Intuitive Criterion.
} 


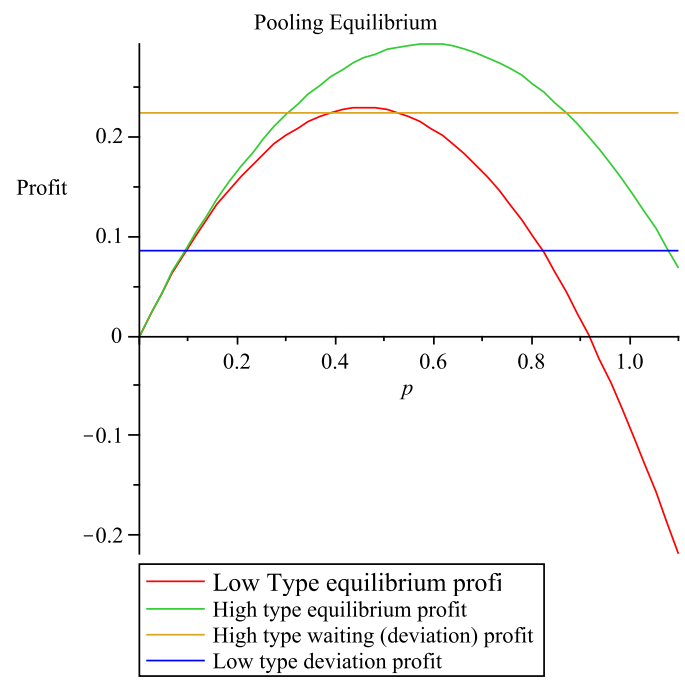

Figure 4: Pooling equilibrium when $.38<p_{1}<.82, \delta=.9, \gamma_{l}=.2, \alpha=.5$

1) Assume $\gamma_{l}<\frac{\delta}{2+\delta}$. We will show such equilibria exist if the pooling price $p_{1}$ consumers believe is in the range of:

$$
\frac{\delta(2+\delta)\left[\gamma_{l}+\alpha\left(1-\gamma_{l}\right)\right]}{4\left[(2+\delta)\left(\alpha\left(1-\gamma_{l}\right)+\gamma_{l}\right)\right]-2 \delta}<p_{1}<\frac{(2+\delta)\left[\gamma_{l}+\alpha\left(1-\gamma_{l}\right)\right]}{2}
$$

and

$$
\begin{array}{r}
\frac{\left[\alpha\left(1-\gamma_{l}\right)+\gamma_{l}\right](\delta+2)^{2}\left\{(4+\delta)\left(\alpha\left(1-\gamma_{l}\right)+\gamma_{l}\right)-\sqrt{\alpha\left(1-\gamma_{l}\right)(\delta+4)\left[4 \gamma_{l}+\alpha\left(1-\gamma_{l}\right)(4+\delta)\right]}\right\}}{2(4+\delta)\left[2(2+\delta)\left(\alpha+\gamma_{l}-\alpha \gamma_{l}\right)-\delta \gamma_{l}\right]}<p_{1}< \\
\frac{\left[\alpha\left(1-\gamma_{l}\right)+\gamma_{l}\right](\delta+2)^{2}\left\{(4+\delta)\left(\alpha\left(1-\gamma_{l}\right)+\gamma_{l}\right)+\sqrt{\alpha\left(1-\gamma_{l}\right)(\delta+4)\left[4 \gamma_{l}+\alpha\left(1-\gamma_{l}\right)(4+\delta)\right]}\right\}}{2(4+\delta)\left[2(2+\delta)\left(\alpha+\gamma_{l}-\alpha \gamma_{l}\right)-\delta \gamma_{l}\right]}
\end{array}
$$

Note that this range is not empty since figure 4 gives a pooling equilibrium example.

To prove this, first, let us calculate the no-deviation range for the high-type monopolist. In a pooling equilibrium, $\mu_{1 B}=\alpha$; hence,

$$
\Pi_{\text {HighPool }}=V_{\gamma=1}\left(p_{1}, \alpha\right)=p_{1}\left(1-\frac{2 p_{1}}{(2+\delta)\left(\alpha+\gamma_{l}-\alpha \gamma_{l}\right)}\right)+\frac{\delta}{4}\left(\frac{2 p_{1}}{(2+\delta)\left(\alpha+\gamma_{l}-\alpha \gamma_{l}\right)}\right)^{2}
$$

The high type monopolist can deviate in two different ways. One way is posing as low type in the first period. The other way is announcing/waiting in the first period and selling in the second period. If it poses as a low type, its profit is $\pi_{\text {HighPoolDev }}=\frac{\gamma_{l}^{2}(2+\delta)^{2}}{4\left(4 \gamma_{l}+2 \gamma_{l} \delta-\delta\right)}$. Its waiting equilibrium profit is $\frac{\delta}{4} \cdot{ }^{21}$ A quick calculation shows that when our assumption in the

\footnotetext{
${ }^{21}$ Note that the out of equilibrium path is not important for this equilibrium since the monopolist will not sell in the first period by announcing to wait, and then consumers will learn the type in the second period.
} 
proposition, $\gamma_{l}<\frac{\delta}{2+\delta}$, holds, then waiting equilibrium is higher than posing as a low type equilibrium. Therefore, the high-type will not deviate if its profit in the pooling equilibrium is greater than or equal to the profit of waiting equilibrium which is $\frac{\delta}{4}$. Just as the previous case, we define a function that shows the difference of equilibrium profit and deviation profit, and find its roots.

$$
g\left(p_{1}\right)=p_{1}\left(1-\frac{2 p_{1}}{-2 \alpha-\alpha \delta-2 \gamma_{l}-\gamma_{l} \delta+2 \gamma_{l} \alpha+\gamma_{l} \alpha \delta}\right)+\frac{\delta}{4}\left(\frac{-2 p_{1}}{-2 \alpha-\alpha \delta-2 \gamma_{l}-\gamma_{l} \delta+2 \gamma_{l} \alpha+\gamma_{l} \alpha \delta}\right)^{2}-\frac{\delta}{4}
$$

The roots are:

$$
\begin{aligned}
& \text { root }_{\text {hightype } 2}=\alpha+\frac{1}{2} \alpha \delta+\gamma_{l}+\frac{1}{2} \gamma_{l} \delta-\gamma_{l} \alpha-\frac{1}{2} \gamma_{l} \alpha \delta=\frac{(2+\delta)\left[\gamma_{l}+\alpha\left(1-\gamma_{l}\right)\right]}{2} \\
& \text { root }_{\text {hightype } 1}=\frac{(1 / 2) \delta\left(-2 \alpha-\alpha \delta-2 \gamma_{l}-\gamma_{l} \delta+2 \gamma_{l} \alpha+\gamma_{l} \alpha \delta\right)}{\left(2 \gamma_{l} \alpha \delta-2 \alpha \delta+4 \gamma_{l} \alpha-4 \alpha-2 \gamma_{l} \delta+\delta-4 \gamma_{l}\right)}=\frac{\delta(2+\delta)\left[\gamma_{l}+\alpha\left(1-\gamma_{l}\right)\right]}{2\left[2(2+\delta)\left(\alpha\left(1-\gamma_{l}\right)+\gamma_{l}\right)-\delta\right]}
\end{aligned}
$$

If $p_{1}$ is between the roots above and $\gamma_{l}<\frac{\delta}{2+\delta}$, then we get the no-deviation range for the high-type monopolist. Note that $p_{1}<$ root $_{\text {hightype } 2}$ ensures that $\theta_{1}$ is less than 1 (see equation 2). In other words, it guarantees that waiting equilibrium payoff is not greater than pooling equilibrium payoff.

For the low type, profit in a pooling equilibrium ${ }^{22}$ is:

$$
\Pi_{\text {LowPool }}=V_{\gamma_{l}}\left(p_{1}, \alpha\right)=p_{1}\left(1-\frac{2 p_{1}}{(2+\delta)\left[\alpha+(1-\alpha) \gamma_{l}\right]}\right)+\frac{\delta \gamma_{l}}{4}\left(\frac{2 p_{1}}{(2+\delta)\left[\alpha+(1-\alpha) \gamma_{l}\right]}\right)^{2}
$$

Its deviation profit is:

$$
\Pi_{\text {LowPoolDev }}=\frac{\gamma_{l}(\delta+2)^{2}}{4(4+\delta)}
$$

The roots of the difference function, $\Pi_{\text {LowPool }}-\Pi_{\text {LowPoolDev }}$, is:

$$
\begin{aligned}
& \Pi_{\text {LowPool }}-\Pi_{\text {LowPoolDev }}=p_{1}\left(1-\frac{2 p_{1}}{(2+\delta)\left[\alpha+(1-\alpha) \gamma_{l}\right]}\right)+\frac{\delta \gamma_{l}}{4}\left(\frac{2 p_{1}}{(2+\delta)\left[\alpha+(1-\alpha) \gamma_{l}\right]}\right)^{2}-\frac{\gamma_{l}(\delta+2)^{2}}{4(4+\delta)} \\
& \Leftrightarrow p^{2} 4(4+\delta)\left\{2(2+\delta)\left[\alpha+(1-\alpha) \gamma_{l}\right]-\delta \gamma_{l}\right\}-p 4(4+\delta)(2+\delta)^{2}\left[\alpha+(1-\alpha) \gamma_{l}\right]^{2}+\gamma_{l}(2+
\end{aligned}
$$

$$
\begin{aligned}
\delta)^{4}\left[\alpha+(1-\alpha) \gamma_{l}\right]^{2}=0 \\
\operatorname{root}_{\text {lowtype } 2}=\frac{\left[\alpha\left(1-\gamma_{l}\right)+\gamma_{l}\right](\delta+2)^{2}\left\{(4+\delta)\left(\alpha\left(1-\gamma_{l}\right)+\gamma_{l}\right)+\sqrt{\alpha\left(1-\gamma_{l}\right)(\delta+4)\left[4 \gamma_{l}+\alpha\left(1-\gamma_{l}\right)(4+\delta)\right]}\right.}{2(4+\delta)\left[2(2+\delta)\left(\alpha+\gamma_{l}-\alpha \gamma_{l}\right)-\delta \gamma_{l}\right]} \\
\text { root }_{\text {lowtype } 1}=\frac{\left[\alpha\left(1-\gamma_{l}\right)+\gamma_{l}\right](\delta+2)^{2}\left\{(4+\delta)\left(\alpha\left(1-\gamma_{l}\right)+\gamma_{l}\right)-\sqrt{\alpha\left(1-\gamma_{l}\right)(\delta+4)\left[4 \gamma_{l}+\alpha\left(1-\gamma_{l}\right)(4+\delta)\right]}\right\}}{2(4+\delta)\left[2(2+\delta)\left(\alpha+\gamma_{l}-\alpha \gamma_{l}\right)-\delta \gamma_{l}\right]}
\end{aligned}
$$

This gives the no-deviation range for the low-type monopolist. As we combine the nodeviation conditions for high and low type, we get pooling equilibria (see figure 4 for an example).

Case 2) Assume $\gamma_{l}>\frac{\delta}{2+\delta}$. The only thing that will change is that if the high type deviates, it will deviate to pose as a low type rather than to deviate to wait.

\footnotetext{
${ }^{22}$ If the high type does not find waiting profitable, then the low type definitely does not find it profitable.
} 


$$
\begin{aligned}
& \Pi_{\text {HighPool }}-\pi_{\text {HighPoolDev }}=p_{1}\left(1-\frac{2 p_{1}}{(2+\delta)\left(\alpha+\gamma_{l}-\alpha \gamma_{l}\right)}\right)+\frac{\delta}{4}\left(\frac{2 p_{1}}{(2+\delta)\left(\alpha+\gamma_{l}-\alpha \gamma_{l}\right)}\right)^{2}-\frac{\gamma_{l}^{2}(2+\delta)^{2}}{4\left(4 \gamma_{l}+2 \gamma_{l} \delta-\delta\right)}=0 \\
& \Leftrightarrow p_{1} 4\left(4 \gamma_{l}+2 \gamma_{l} \delta-\delta\right)(2+\delta)^{2}\left(\alpha+\gamma_{l}-\alpha \gamma_{l}\right)^{2}-2 p_{1}^{2} 4\left(4 \gamma_{l}+2 \gamma_{l} \delta-\delta\right)(2+\delta)\left(\alpha+\gamma_{l}-\alpha \gamma_{l}\right)+ \\
& 4 \delta p_{1}^{2}\left(4 \gamma_{l}+2 \gamma_{l} \delta-\delta\right)-\gamma_{l}^{2}(2+\delta)^{4}\left(\alpha+\gamma_{l}-\alpha \gamma_{l}\right)^{2}=0 \\
& \Leftrightarrow \text { root }_{\text {hightype } 2,1}=\frac{(2+\delta)^{2}\left(\alpha+\gamma_{l}-\alpha \gamma_{l}\right)\left\{\left(4 \gamma_{l}+2 \gamma_{l} \delta-\delta\right)\left(\alpha\left(1-\gamma_{l}\right)+\gamma_{l}\right)-\sqrt{\alpha\left(1-\gamma_{l}\right)\left(4 \gamma_{l}+2 \gamma_{l} \delta-\delta\right)\left[\left(4 \gamma_{l}+2 \gamma_{l} \delta-\delta\right)\left(\alpha+\gamma_{l}-\alpha \gamma_{l}\right)-\delta \gamma_{l}\right]}\right\}}{2\left(4 \gamma_{l}+2 \gamma_{l} \delta-\delta\right)\left[2(2+\delta)\left(\alpha\left(1-\gamma_{l}\right)+\gamma_{l}\right)-\delta\right]} \\
& \Leftrightarrow \text { root }_{\text {hightype } 2,2}=\frac{(2+\delta)^{2}\left[\alpha\left(1-\gamma_{l}\right)+\gamma_{l}\right]\left\{\left(4 \gamma_{l}+2 \gamma_{l} \delta-\delta\right)\left(\alpha\left(1-\gamma_{l}\right)+\gamma_{l}\right)+\sqrt{\alpha\left(1-\gamma_{l}\right)\left[2 \gamma_{l}(2+\delta)-\delta\right]\left[2(1-\alpha)(2+\delta) \gamma_{l}^{2}+[(3 \alpha-2) \delta+4 \alpha] \gamma_{l}-\delta \alpha\right\}}\right.}{2\left(4 \gamma_{l}+2 \gamma_{l} \delta-\delta\right)\left[2(2+\delta)\left(\alpha\left(1-\gamma_{l}\right)+\gamma_{l}\right)-\delta\right]}
\end{aligned}
$$

For the low type, no-deviation range is still the same as Case 1. Hence, when price is between

$$
\operatorname{Max}\left\{\operatorname{root}_{\text {hightype } 2,1}, \operatorname{root}_{\text {lowtype } 1}\right\}<p_{1}<\operatorname{Min}\left\{\operatorname{root}_{\text {hightype } 2,2}, \operatorname{root}_{\text {lowtype } 2}\right\}
$$

and $\gamma_{l}>\frac{\delta}{2+\delta}$, we have a pooling equilibrium.

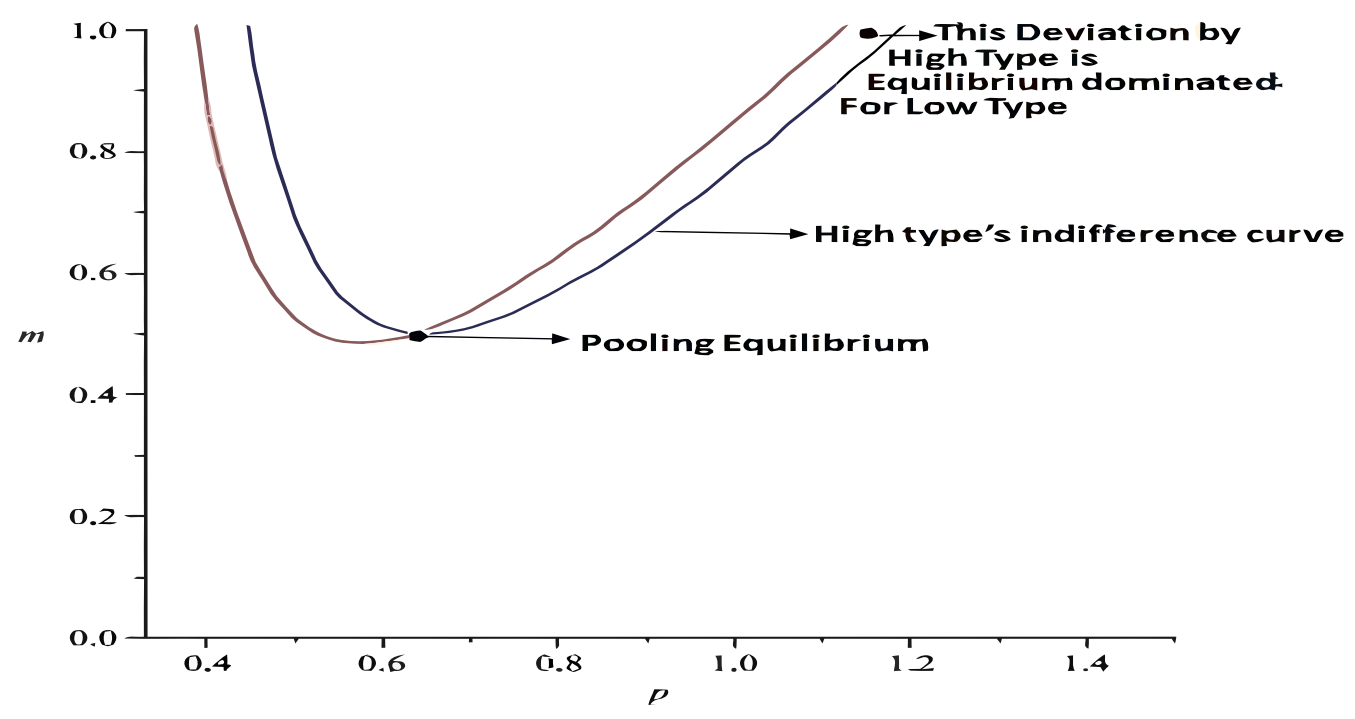

Figure 5: Indifference Curves at the Pooling equilibrium when $p_{1}=.635, \delta=.8, \gamma_{l}=.5$, $\alpha=.5$ The high type's (low type's) is the one shifted further right (left). Preferable pairs of $\left(p_{1}, \mu_{1 B}\right)$ lies inside for both types. High type may deviate to $p_{1}=1.15$ which is equilibrium dominated for low type (even when $\mu_{1 B}=1$ ); hence, Intuitive Criterion does not hold.

When $\gamma_{l}>0$, these pooling equilibria do not satisfy the Intuitive Criterion. For any pooling equilibrium $\left(p_{1}, \mu_{1 B}\right)$, we calculate the indifference curve, $V_{\gamma}\left(p_{1}, \mu_{1 B}\right)$, (where $\gamma \in$ $\left.\left\{1, \gamma_{l}\right\}\right)$ for both types. We will show that these indifference curves satisfy the Spence-Mirrlees condition (i.e., single crossing property). But then, we can show that high type monopolist will deviate to a (very high) price that the low type will not deviate even if consumers' belief 
change to $\mu_{1 B}=1$ after observing such a deviation (See Figure 5). Therefore, the pooling equilibria do not satisfy the intuitive criterion.

First, we calculate the following partial derivatives:

$$
\begin{gathered}
\frac{d V}{d p_{1}}\left(\gamma, \mu_{1 B}, p_{1}\right)=1-\frac{4 p_{1}}{\left((2+\delta)\left(\mu_{1 B}+\left(1-\mu_{1 B}\right) \gamma_{l}\right)\right)}+\frac{2 \delta \gamma p_{1}}{\left((2+\delta)^{2}\left(\mu_{1 B}+\left(1-\mu_{1 B}\right) \gamma_{l}\right)^{2}\right)} \\
\frac{d V}{d \mu_{1 B}}=\frac{2 p_{1}^{2}\left(1-\gamma_{l}\right)}{\left((2+\delta)\left(\mu_{1 B}+\left(1-\mu_{1 B}\right) \gamma_{l}\right)^{2}\right)}-\frac{2 \delta \gamma p_{1}^{2}\left(1-\gamma_{l}\right)}{\left((2+\delta)^{2}\left(\mu_{1 B}+\left(1-\mu_{1 B}\right) \gamma_{l}\right)^{3}\right)}
\end{gathered}
$$

By using the equations above, we calculate the following derivative (and we can take the derivative since $\gamma_{l}>0:^{23}$

$$
\frac{-d\left(\frac{d V / d p_{1}}{d V / d \mu_{1 B}}\right)}{d \gamma}=-\left(\frac{(2+\delta)\left(-\delta \mu_{1 B}-\delta \gamma_{l}+\delta \gamma_{l} \mu_{1 B}-2 \mu_{1 B}+2 \gamma_{l} \mu_{1 B}+2 p_{1}-2 \gamma_{l}\right)\left(-\mu_{1 B}-\gamma_{l}+\gamma_{l} \mu_{1 B}\right)^{2} \delta}{2\left(p_{1}^{2}\left(-2 \mu_{1 B}-2 \gamma_{l}+2 \gamma_{l} \mu_{1 B}-\delta \mu_{1 B}-\delta \gamma_{l}+\delta \gamma_{l} \mu_{1 B}+\delta \gamma\right)^{2}\left(-1+\gamma_{l}\right)\right)}\right.
$$

But then $-d\left(\frac{d V / d p_{1}}{d V / d \mu_{1 B}}\right) /(d \gamma)$ is always negative since the denominator is negative $\left(-1+\gamma_{l}<\right.$ 0 ) and the numerator is also positive since

$$
\left(-\delta \mu_{1 B}-\delta \gamma_{l}+\delta \gamma_{l} \mu_{1 B}-2 \mu_{1 B}+2 \gamma_{l} \mu_{1 B}+2 p_{1}-2 \gamma_{l}\right) \Leftrightarrow p_{1}<\frac{(2+\delta)\left(\gamma_{l}+\alpha\left(1-\gamma_{l}\right)\right.}{2}
$$

The right hand side of the equation above should hold in any pooling equilibrium; otherwise, $\theta_{1}>1$ holds and that means waiting equilibrium payoff will be greater than pooling equilibrium payoff for the high type.

This is the Spence-Mirrlees condition so the single crossing holds. In addition, this shows that the derivative of low type's indifference curve (at the crossing point) is greater than the high type's; hence, low type's indifference curve touches $\mu_{1 B}=1$ at a lower price (say $p_{l}$ ) than the high type's. If the high type deviates to a price slightly greater than this $p_{l}$, then the low type would not follow high type even under the belief $\mu_{1 B}=1$. Hence, intuitive criterion will be violated.

\footnotetext{
${ }^{23}$ Note that by dividing those derivatives, we get $\frac{-d \mu_{1 B}}{d p_{1}}$ which is the slope of the indifference curves.
} 
However, when $\gamma_{l}=0$, given the belief that $\mu_{1 B}=\alpha$, now the low type will always mimic the high type in the first period, and no $p_{1}$ can be equilibrium dominated for the low type since it will be making zero profits if consumers knew/learned that it is a low type. Hence, the pooling equilibrium satisfies the Intuitive Criterion for $\gamma_{l}=0$ case.

This concludes our proof.

\section{Proof of Proposition 3:}

For a given equilibrium we compare the equilibrium prices we computed for any pooling equilibrium. For part a), we have

$$
p_{1}<p_{2}=\frac{p_{1}}{(2+\delta)\left(\alpha+\gamma_{l}+\alpha \gamma_{l}\right)} \Longleftrightarrow \delta<\frac{1-2\left(\alpha+\gamma_{l}-\alpha \gamma_{l}\right)}{\left(\alpha+\gamma_{l}-\alpha \gamma_{l}\right)}
$$

Note that $p_{2}=\frac{\theta_{1}}{2}$ (from the second period maximization problem of the high type monopolist).

Proof of part b follows from part a.

Proof of Proposition 6: We will show that such an equilibrium exists when $\gamma_{l}<\frac{\delta}{2+\delta}$ and consumers believe that any firm selling in the first period is a low type. ${ }^{24}$

The waiting profit of the high-type firm is given by $\pi_{w a i t}=\frac{\delta}{4}$, since $\theta_{1}=1$.

The profits of the high firm posing as a low firm is the same as in equation 9, which is

$$
\pi_{\text {HighDev }}=\frac{(2+\delta)^{2} \gamma_{l}^{2}}{4\left(4 \gamma_{l}+2 \delta \gamma_{l}-\delta\right)}
$$

For the firm to wait, and not deviate and pose as a low type, the profits of waiting must be greater than or equal to the profits of deviating as a low type. The root of the function $\pi_{\text {wait }}-\pi_{\text {HighDev }}$ is $\gamma_{l}=\delta /(2+\delta)$. When $\gamma_{l}<\frac{\delta}{2+\delta}$, the waiting profit will be higher, and hence, the high type waits for the second period to sell.

If $\gamma_{l}=0$ holds, then no $p_{1}$ can be equilibrium dominated for the low type since it is already making zero profits. Hence, this satisfies the Intuitive Criterion. If $\gamma_{l}$ is positive,

\footnotetext{
${ }^{24}$ There may be other waiting equilibrium for different parameter ranges with different beliefs so we do not claim that this is the only waiting equilibrium. This equilibrium, however, is sufficient to show "waiting equilibrium" exists.
} 
then assume that high type deviates to some $p_{1} \in\left(\operatorname{rootlow} 2, \min \left\{\operatorname{roothigh} 2, \frac{2+\delta}{2}\right\}\right)$. we have already showed in the separating equilibrium proof that these price ranges are equilibrium dominated for low type even under the belief $\mu_{1 B}=1$ but is profitable for the high type compared to waiting. Therefore, such equilibria cannot satisfy intuitive criterion.

\section{Appendix B}

\subsection{Separating Equilibrium Case}

Here, we will calculate the welfare under the separating equilibrium that satisfies the intuitive criterion. This is when ${ }^{25}$

$$
p_{1}=\text { rootlow } 2=\frac{\left[(2+\delta)^{2}\left[4+\delta+\sqrt{(4+\delta)\left(1-\gamma_{l}\right)\left[\delta\left(1-\gamma_{l}\right)+4\right)}\right]\right.}{2(4+\delta)\left(\delta\left(2-\gamma_{l}\right)+4\right)}
$$

Let us first calculate the welfare under the high type monopolist, then we will turn to the low type monopolist. Finally, we will add these welfare calculations to solve for the total ex-ante expected welfare.

The profit of high type monopolist in a separating equilibrium is $V_{\gamma=1}\left(p_{1}=\right.$ rootlow $2, \mu_{1 B}=$ 1). To calculate social welfare, we need $\theta_{1}$, and it can be calculated from equation 2 .

$$
\theta_{1}\left(p_{1}=\text { rootlow } 2, \mu_{1 B}=1\right)=\frac{-(2+\delta)\left(4+\delta+\sqrt{(4+\delta)\left(-1+\gamma_{l}\right)\left(-\delta+\delta \gamma_{l}-4\right)}\right)}{\left((4+\delta)\left(-2 \delta+\delta \gamma_{l}-4\right)\right)}
$$

In the equilibrium, we have $\theta_{2}=p_{2}=\frac{\theta_{1}}{2}$. Consumer surplus can be calculated by inserting $\theta_{1}, \theta_{2}, p_{1}$ and $p_{2}$ to the following equation:

$$
C S_{h}=\int_{\theta_{1}}^{1}\left(\theta-p_{1}\right) d \theta+\delta \int_{\theta_{2}}^{\theta_{1}}\left(\theta-p_{2}\right) d \theta
$$

After taking the integral and simplifying, and adding the profit, we calculate the welfare under the high type monopolist in a separating equilibrium. ${ }^{26}$ Since, the expression is cumbersome, we provide its three dimensional graph in figure 6. While drawing the graph, we assumed $\alpha=1$.

\footnotetext{
${ }^{25}$ In the proofs, we demonstrate that $p_{1}=$ rootlow 2 satisfies the intuitive criterion.

${ }^{26}$ MAPLE is used in making these calculations and drawing the graphs. It is available from the authors.
} 

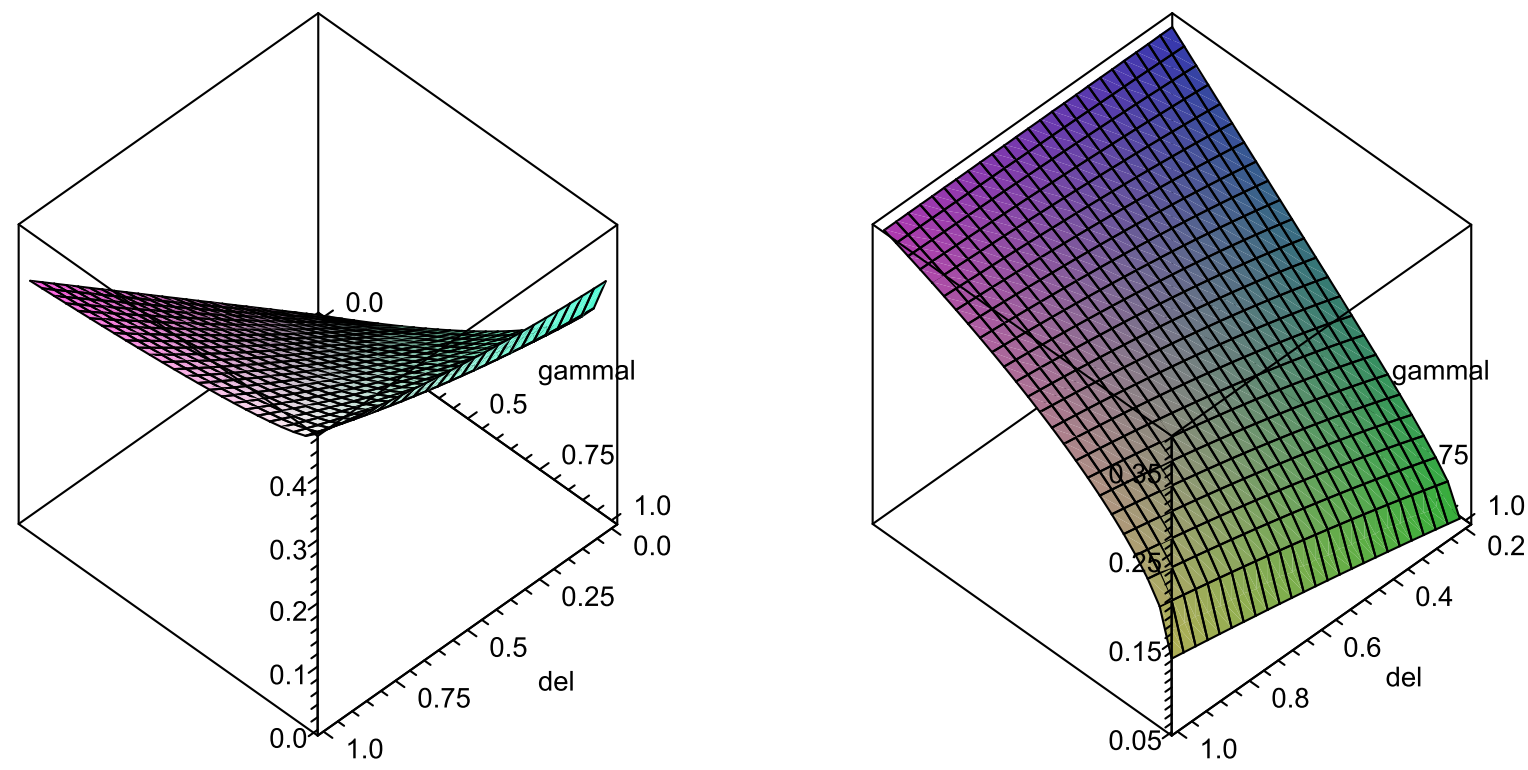

Figure 6: Welfare under a high-type monopolist (on the left) and its (always positive) derivative w. r. t. $\delta$ (on the right)
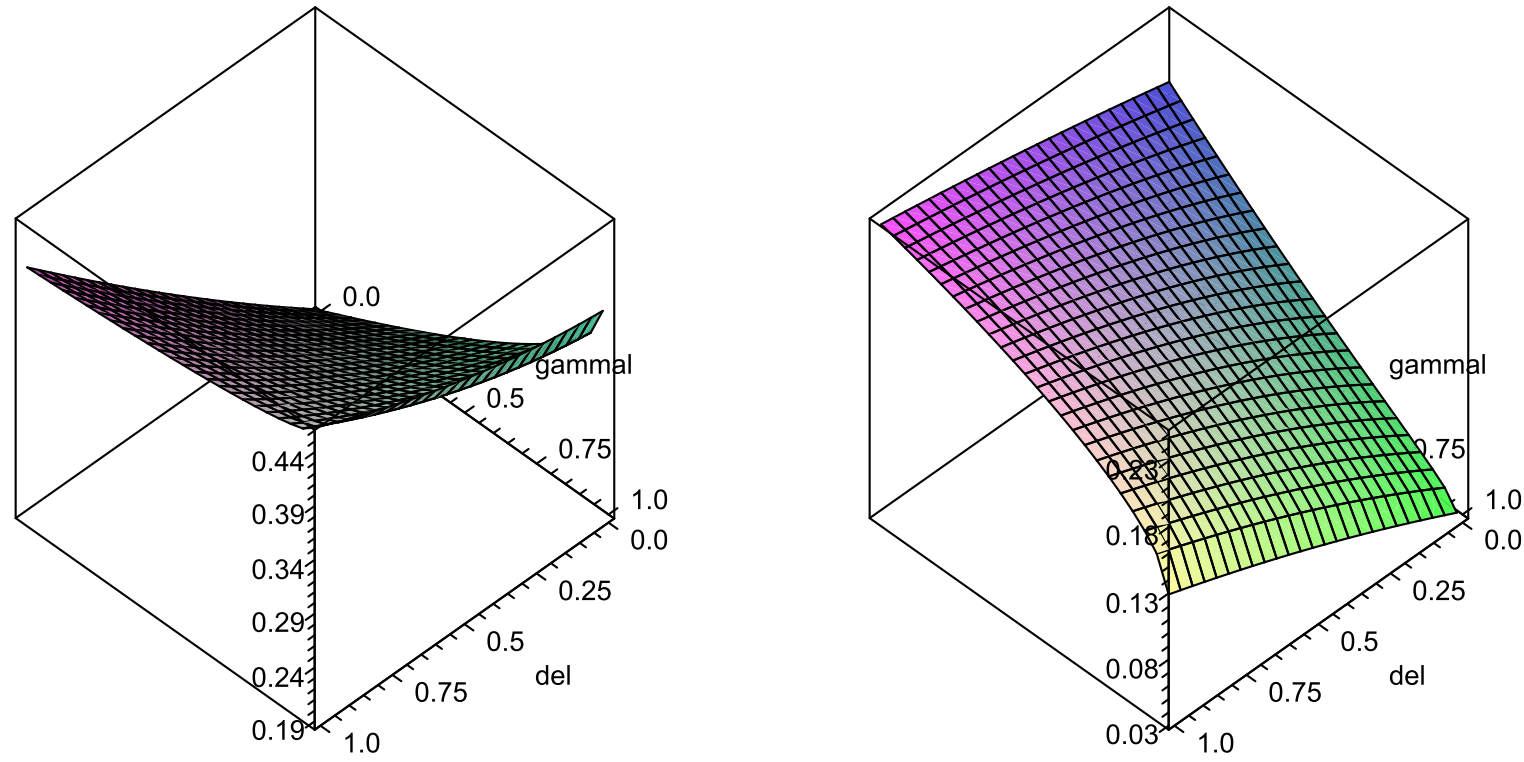

Figure 7: Welfare (on the left) and Derivative of Welfare w. r. t. $\delta$ (on the right) 
As expected, welfare increases with $\gamma_{l}$ since this will decrease signalling cost for the hightype. This is clear from the first graph in figure 6 . It also increases with $\delta$. As delta increases, price increases and hence less consumers buy the good. This decreases consumer surplus. However, profit always increases as delta increases. The net effect is positive.

Now, we will calculate the welfare under a low type monopolist in a separating equilibrium. The low type monopolist actually produces the amounts it would produce in a perfect information model in a separating equilibrium.

The profit is $V_{l}\left(p_{1}=\frac{(2+\delta)^{2} \gamma_{l}}{2(4+\delta)}, \mu_{1 B}=0\right)=\frac{\gamma_{l}(2+\delta)^{2}}{4(4+\delta)}$. To calculate the consumer surplus, we need $\theta_{1}=\frac{2+\delta}{4+\delta}, \theta_{2}=\frac{2+\delta}{2(4+\delta)}, p_{2}=\gamma_{l} \frac{2+\delta}{2(4+\delta)}$.

$$
C S_{l}=\int_{\theta_{1}=\frac{2+\delta}{4+\delta}}^{1}\left(\theta-\frac{(2+\delta)^{2} \gamma_{l}}{2(4+\delta)}\right) d \theta+\delta \int_{\frac{2+\delta}{2(4+\delta)}}^{\frac{2+\delta}{(4+\delta)}}\left(\theta-\gamma_{l} \frac{2+\delta}{2(4+\delta)}\right) d \theta
$$

Taking the integral, we have,

$$
C S_{l}=\frac{1}{8(4+\delta)^{2}}\left[3 \delta^{3}+12 \delta^{2}+28 \delta+48-2 \delta^{3} \gamma_{l}-16 \delta^{2} \gamma_{l}-40 \delta \gamma_{l}-32 \gamma_{l}\right]
$$

then,by adding the profit, we have the welfare when we have a low type:

$$
W_{l}=\frac{3 \delta^{3}+12 \delta^{2}+28 \delta+48-2 \delta^{3} \gamma_{l}-16 \delta^{2} \gamma_{l}-40 \delta \gamma_{l}-32 \gamma_{l}}{8(4+\delta)^{2}}+\frac{\gamma_{l}(2+\delta)^{2}}{4(4+\delta)}
$$

Total expected welfare is $\alpha W_{h}+\left(1-\alpha W_{l}\right)$. However, calculating total expected welfare analytically is cumbersome so we give its three dimensional graph in figure 7 . We assume $\alpha=\frac{1}{2}$ while drawing the graph. The graph shows that welfare increases as $\gamma_{l}$ increases; as $\gamma_{l}$ increases, the cost of signalling for high-type decreases; hence, the welfare increases. The derivative of welfare with respect to delta is positive.

Let us now calculate the efficiency loss for the separating equilibrium. The low type produces the same output in both perfect information and separating equilibrium. The loss comes from the high type's signalling effort. We have already calculated welfare when there is a high type monopolist under perfect information and under separating equilibrium. By subtracting these welfare and multiplying with $\alpha$, we calculate the efficiency loss. We report its three dimensional graph in figure 8 (while drawing the graph, we used $\alpha=1$. As 

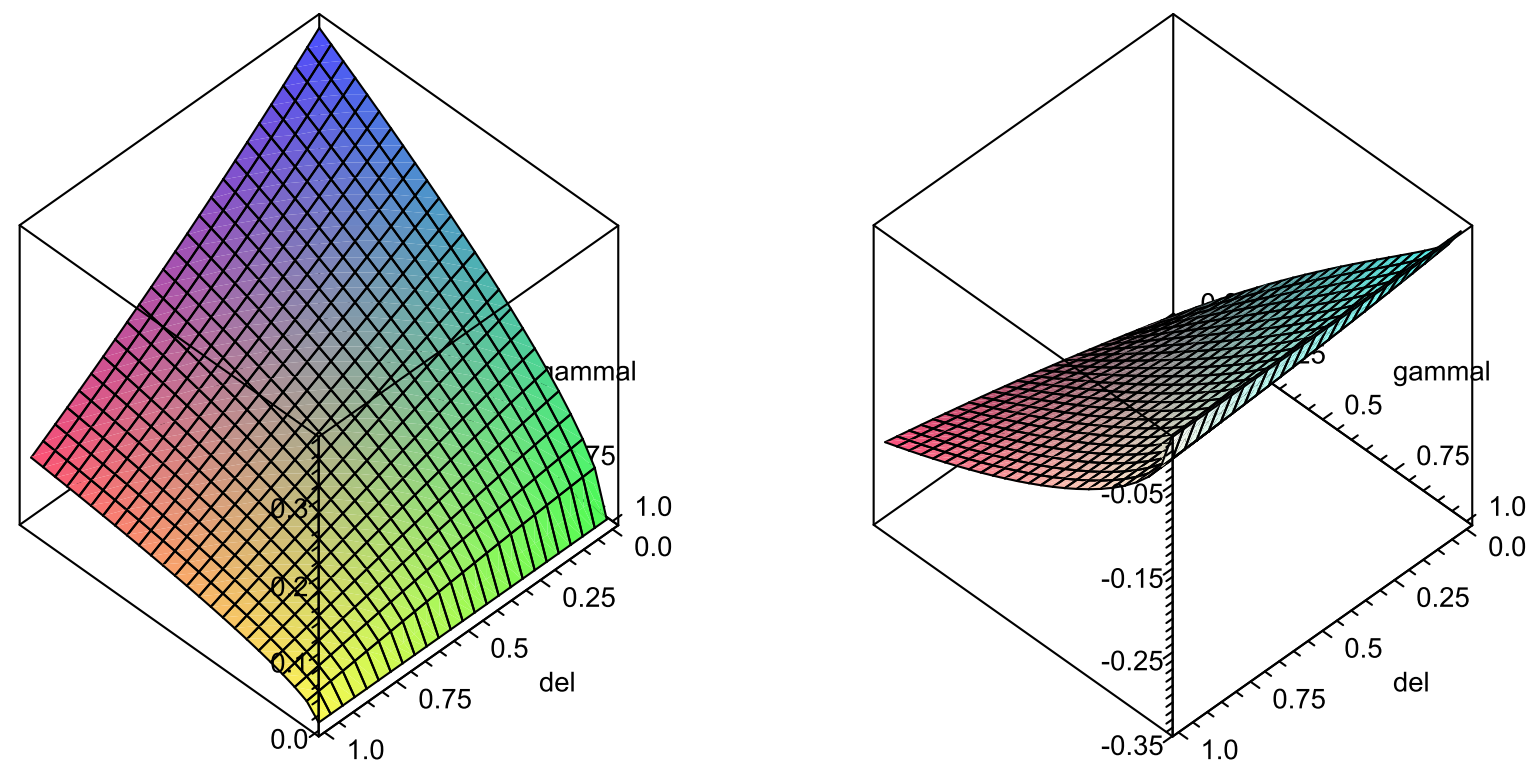

Figure 8: Efficiency Loss and its derivative w. r. t. $\delta$

the probability of having a high-type monopolist increases, efficiency loss decreases.) and show that efficiency loss decreases as delta increases. Welfare under separating equilibrium increases faster as delta increases. The cost of signalling must be decreasing as agents become more patient.

\section{References}

[1] Aoyagi, M., 1998, "Equilibrium delay in a simple dynamic model of investment," Economic Theory, 12, 123-146

[2] Bagwell, K. and H. M. Riordan, 1991 "High and Declining Prices Signal Product Quality," American Economic Review 81, 224-239.

[3] Bayus, B. L., S. Jain, and A. G. Rao., 2001 "Truth or Consequences: An Analysis of Vaporware and New Product Announcements," Journal of Marketing Research, 38, 3-13.

[4] Bergemann, D. and J. Valimaki., 2006 "Dynamic Pricing of New Experience Goods," Journal of Political Economy, 114, 713-743. 
[5] Bhalla, M. (2011) "Waterfall versus Sprinkler Product Launch Strategy: Influencing the Herd." Journal of Industrial Economics. Forthcoming.

[6] Bose, S.; Orosel, G.; Ottaviani, M. and Vesterlund, L., 2008, "Monopoly Pricing in the Binary Herding Model", Economic Theory, 37, pp. 203-41.

[7] Cho, I., D. Kreps., 1987 "Signalling Games and Stable Equilibria," Quarterly Journal of Economics, 102, 179-221.

[8] Choi, J. P., E. G. Kristiansen, and J. Nahm., 2010, "Vaporware" International Economic Review, 51, 653-669.

[9] Coase R., 1972, "Durability and Monopoly," Journal of Law and Economics, 15, 143149.

[10] Cremer, J. 1984, "On the Economics of Repeat Buying," Rand Journal of Economics $15,396-403$.

[11] Dranove D. and N. Gandal, 2003, "The DVD and DIVX Standard War: Empirical Evidence of Vaporware" Journal of Economics and Management Strategy, 12, 363-386.

[12] Gunay, H., 2008a, "The role of externalities and information aggregation in market collapse," Economic Theory, 35, 367-379.

[13] Gunay, H., 2008b, "Information aggregation under strategic delay," Economics Bulletin, $12,1-8$

[14] Gul F., H. Sonnenschein, R. Wilson, 1986, "Foundations of Dynamic Monopoly and the Coase Conjecture," Journal of Economic Theory, 39, 155-190.

[15] Heidhues, P., and N. Melissas, 2006, "Equilibria in a dynamic global game: The role of cohort effects," Economic Theory, 28, 531-557

[16] Jing, B., 2011, "Pricing Experience Goods: The Effects of Customer Recognition and Committment," Journal of Economics and Management Strategy, 20, 451-473 
[17] Koh, W., 2006 "The micro-foundations of intertemporal price discrimination," Economic Theory, 27, 393-410.

[18] Kristiansen, E. G., 2006 "R\&D and buyer's waiting option" Journal of Industrial Economics, 54, 31-42.

[19] Lopomo, G. and F. Squintani 2007, "Signalling Quality by Delaying Sales," Working Paper.

[20] Milgrom P. and J. Roberts 1986, "Price and Advertising Signals of Product Quality," Journal of Political Economy, 94, p.796-821.

[21] Shapiro, C., 1983, "Optimal pricing of experience goods," Bell Journal of Economics, $14,497-507$.

[22] Stokey, N., 1979, "Intertemporal Price Discrimination," Quarterly Journal of Economics, 94, 355-371.

[23] Tirole, J., 1989, The Theory of Industrial Organization. MIT Press. Cambridge; Mass.

[24] Van Ackere, A. and D. Reyniers., 1995 "Trade-ins and Introductory Offers in a Monopoly," Rand Journal of Economics, 26, 58-74.

[25] Wildstrom, S. H., 2009, "Microsoft gets it right (finally)," Business Week, October 26 issue, page 71 . 